\title{
Emergent Properties of the Public Realm and Encroachments in the Urban Environment
}

\author{
Akshay P. Patil • Alpana R. Dongre
}

Published online: 28 May 2014

(C) Kim Williams Books, Turin 2014

\begin{abstract}
The declining quality of the public realm in urban environment is a matter of concern and is found to be encroached upon in Indian cities. There is an urgent need to address this issue, and it is challenging for urban designers. Adopting an analytic framework addressing this ever-changing nature of the public realm in practice would be instrumental in improving the quality of urban life at large. The public realm in an urban environment is considered as a complex system to observe the macro-level behaviouremergent properties which are either encouraging or discouraging for encroachments assumed to be the function of micro-level behaviour-elementary properties of interconnected and interdependent individual elements. Owing to the impossibility of experimenting with these emergent properties in the real world, an agent-based model"Emergent Properties of Public Realm 3.1"-was developed in NetLogo 4.1.3. The typical cases representing the encroached and the un-encroached public realm were identified in the real world and experiments were conducted with varied interaction constants assumed to represent the pace of change in an urban environment. The output generated by the agent-based model was analyzed with respect to the real world.
\end{abstract}

Keywords Urban design · Chaos · Dynamics · Feedback · Iteration · Emergent properties · Agent-based modelling

\section{Introduction}

The public realm in the urban environment is the physical domain which is accessible to all. It is where the greatest amount of human contact and interaction

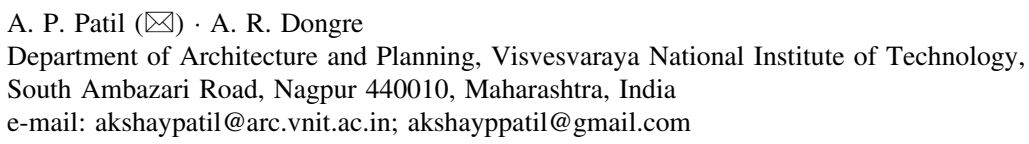


takes place. It is all the parts of the urban fabric to which the public have physical and visual access. Thus, it extends from the streets, parks and squares of a town or city into the buildings which enclose and line them (Tibbalds 1992). The declining quality of the public realm in the urban environment is a matter of concern in Indian cities. The public realm on many occasions is found to be encroached upon (Fig. 1a). Encroachments are the physical manifestation of the informal sector. The activities in the informal sector can be categorized into two sections-selfemployed and casual (non-permanent) labour. A major section of the self-employed work as street vendors. Street vendors may be stationary in the sense that they
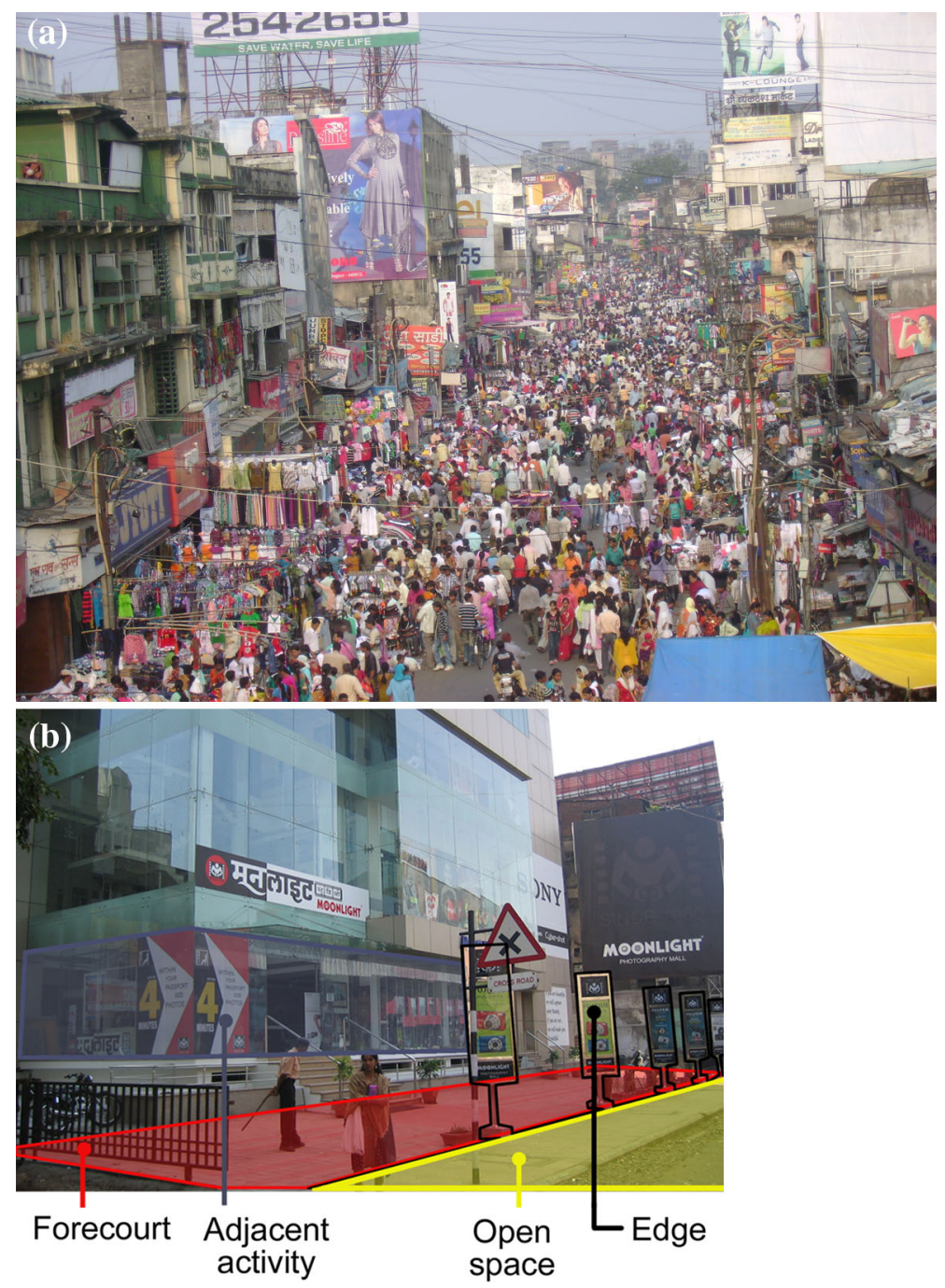

Fig. 1 a The public realm in the urban environment-real world. Photo: Author. b The public realm in the urban environment-elements of the public realm. Photo and Computer rendering: Author 
occupy space on the pavements or other public/private spaces, or they may be mobile in the sense that they move from place to place by carrying their wares on pushcarts or in baskets on their heads (Bhowmik 2005). Vendors are constantly testing the market, and if business picks up in one spot, there will soon be a cluster of vendors there. This will draw more people, and yet more vendors, and many times so many converge that pedestrian traffic slows to a crawl (Whyte 1980). Hawkers and street vendors spread their wares on the pavement and sometimes on the street, causing great inconvenience to the pedestrians and vehicles (Timalsina 2011). The encroachments, in their existing form, generate a lot of disturbances in the public realm. The most commonly observed are: hindrances to the movement network, barriers for experiencing open spaces, no space for parking, challenges to urban management systems and, finally, an adverse impact on the image of a place (Patil and Dongre 2013).

The enforced vigilance on the part of public authority has failed to curb this menace. Whyte (1980) observed that the civic establishment deplores all this and there are enough ordinances to make it illegal for vendors, licensed or not, to do business at any spot where business is good. Many times, the police arrive with trucks to haul the vendors away leading to confrontations that usually draw big crowds who are clearly on the side of the vendors. Anti-encroachments drives, relocation programmes, etc. implemented by public authorities have failed to yield desirable results. It appears that encroachments have become an inseparable part of the public realm. Many spaces that are needed are not provided at all, or plans for them scuttled (Whyte 1980). Many functions in an urban environment are never planned for and what emerges as encroachments are nothing but the entities which house these functions. The activities happening within encroachments have an important role to play in the functioning of the city, but the way they exist in our urban environment becomes an issue of concern (Patil and Dongre 2013). By default, the vendors have become the caterers to the city's outdoor life. They flourish because they are servicing a demand not being met by the regular commercial establishment. The vendor thus fills a void, and this can become quite clear when he is shooed away. A lot of the life of the space goes with him (Whyte 1980).

There is an urgent need to address this issue, but its ever-changing nature poses a barrier to urban designers in doing so. In the Indian context, the public realm and encroachments are the best representation of chaos. The chaotic characteristic of encroachments seems to be a barrier to having insight into the emerging form of encroachments based on the reductionist approach (Patil and Dongre 2013). How can we improve the design and maintenance of a public realm which is currently so starved of imagination and resources (Tibbalds 1992)? The quest is to know how to design, build, and manage the public realm as it increases in size and connectivity with reference to the issue of encroachments. Patil and Dongre (2013) note that the disordered appearance of encroachments is a manifestation of a complex order in the urban environment and there is a need to have an effective framework for analysing the emerging form of encroachments in an urban environment. Any progress in this regard will enable us to develop an appropriate public realm which is essentially used by the urban population and will enhance their experience. 
Adopting such developed models in practice in due course of time would be instrumental in improving the quality of urban life at large.

Tibbalds (1992) notes that we must be careful not to make everything too prescriptive, too neat and tidy. Urban areas are messy and complex, rich and muddled. The process of urban design needs to leave room for messiness and complexity. The public realm in an urban environment considered as a complex system is composed of various interconnected and interdependent elements of the built environment. The elements have elementary properties that interact with each other and influence each other in due course of time. The qualities that result from temporal and spatial differentiation of a system are not reduced to the properties of its components; it is maintained that the interactions between the components result in new properties of the system that cannot be fully predicted and cannot be found in the qualities of the components (Fuchs 2003). Elementary properties acting concurrently lead to emergent properties of the public realm. For Mill and later philosophers such as Broad, higher-level emergent properties in complex systems stem from, and are in addition to, lower level causal interactions. They can be thought of as unexpected behaviors that stem from an interaction between the components of an application and the environment (Johnson 2006). These emergent properties are instrumental in the success of the public realm to reach up to the people's expectations. It is necessary to understand the process of the emergence of complex systems in order to create new forms of complex and robust systems which are prepared for the occurrence of errors and prevent failure as much as possible (Fromm 2004). The exploration of these emergent properties can aid urban designers to address the declining quality of the public realm with reference to the issue of encroachments.

The reductionist approach has its own limitation in having an insight into the public realm. It has been extensively researched upon that the concepts from complexity science have the potential of addressing systems which are dynamic in nature. These concepts can be systematically explored for analyzing the complexity of the built environment in the public realm and their emergent properties. Various concepts from complexity science and urban design explored simultaneously have substantial potential to equip urban designers with processes which will ensure efficient design, implementation, and management of the public realm. This paper intends to initiate a computational model of the public realm for emergent properties assumed to be the function of elementary properties of the elements acting concurrently, helpful to address physical design issues. The bottom-up approach offers a decentralized form of controlling the design, based on the independent behaviour of its parts. In this approach, larger scale problems are solved by solving small scale ones (Duarte et al. 2006). The similar bottom-up approach is adopted for initiating the computational modelling of the public realm. This paper incorporates an agent-based modeling approach to the public realm to observe the macro-level behavior-emergent properties, of the public realm, namely, Encouraging Encroachments Emergent Property (EEEP) and Discouraging Encroachments Emergent Property (DEEP) assumed to be the function of micro-level behaviorelementary properties of the individual elements of the public realm. Owing to the impossibility of experimenting with these emergent properties in the real world, an 
agent-based model Emergent Properties of Public Realm 3.1 (EPPR 3.1) was developed in NetLogo 4.1.3 to conduct related experiments. The typical cases representing encroached and the un-encroached public realm were identified in the real world and based on their observations experiments were conducted using the $E P P R$ 3.1. The output generated by EPPR 3.1 was analyzed with respect to the real world.

\section{Interconnected and Interdependent Elements of the Public Realm}

The public realm, an important part of the city is composed of physical environment (built environment and open spaces) and users (Fig. 1b). City form is usually unintentional, but it is not accidental; a product of decisions made for single, separate purposes, whose interrelationships and side effects have not been fully considered (Barnett 1974). This is very well highlighted by Portugali (2012) in Complexity Theories of Cities: Achievements, Criticism and Potentials as follows:

The answer is implicit in Alexander's paper: For example, in Berkeley at the corner of Hearst and Euclid, there is a drugstore, and outside the drugstore a traffic light. In the entrance to the drugstore there is a newsrack where the day's papers are displayed. When the light is red, people who are waiting to cross the street stand idly by the light; and since they have nothing to do, they look at the papers displayed on the newsrack, which they can see from where they stand. Some of them just read the headlines, others actually buy a paper while they wait. This effect makes the newsrack and the traffic light interactive; the newsrack, the newspapers on it, the money going from people's pockets to the dime slot, the people who stop at the light and read papers, the traffic light, the electric impulses which make the lights change, and the sidewalk which the people stand on form a system - they all work together. They all work together because of the human agents that are involved in the dynamics that, unlike the traffic lights, the newsrack and the headlines, can see and read from a distance, change their trajectory and buy a newspaper. By means of these cognitive capacities the people, the newspapers, the traffic lights and the other spatially fixed objects form a system- "a unit in the city" as Alexander calls it.

The built environment and open spaces are of importance to us in this study and a variety of elements within them, for example adjacent activities, open spaces, forecourts, major functions and edges like compound walls or level differences (Fig. 1b).

\section{Adjacent Activities}

As Whyte (1980) observes, the key feature of the street is retailing-stores, windows with displays, signs to attract your attention, doorways, people going in and out of them. Adjacent activities are the activities of the formal sector housed in built-spaces adjacent to the public realm, having elementary properties as Degree of exposure, Degree of spill over, Supportiveness for complimentary activities, and 
Supportiveness for contrasting activities. An activity of the formal sector needs exposure to operate, and varies with various activities. It can be evaluated based on the way it physically manifests itself, for example a mercantile activity needs higher exposure as opposed to an office. A certain amount of spillover is observed of activities of formal sector activity on to the immediate forecourt. The activities of the formal sector usually need some complimentary activities in the close vicinity to operate efficiently, for example a repair activity next to an automobile spare parts shop (Fig. 1b).

\section{Open Spaces}

Open spaces are identified as the stretch between the plot lines and the carriageway in the public realm. They are put to a variety of uses like pedestrian movement, parking, bus stops, etc. Open spaces have properties such as Evenness of ground surface, and Freedom of accessibility. Evenness of ground surface refers to the surface treatment, for example paved, unpaved, etc. The freedom of accessibility refers to users of the public realm. It is observed that there is variation in the users of the public realm associated with the adjacent activities mentioned in 2.1 (Fig. 1b).

\section{Forecourts}

These forecourts are stretches between the buildings and the related plot line. It is observed that the forecourts are largely under public use, in spite of being under private ownership. Variations are observed in treatment and maintenance of forecourts, which is indicative of the sense of ownership. Forecourts have elementary property as the sense of ownership (Fig. 1b).

\section{Major Functions}

Mukim (2011) notes that the informal sector in South-East Asian cities tends to concentrate in areas of dense population, such as nodes of transportation, or where adjacent activities are entertainment complexes or public markets and also in those localities where they could benefit from product complementarities, and mutual customer attraction. Major functions are defined as large-scale activities from the formal sector in the close vicinity of the public realm that attracts considerable users. Major functions have the property of being of catalytic nature. Catalytic nature refers to the ability of major functions to increase the number of users in the public realm. As Patil and Dongre (2013) observe, a major function attracts a lot of people and, in turn, has the potential of promoting other activities in the vicinity. Observation reveals that encroachments are also part of these promoted activities. The catalytic property of functions such as theatre, cultural complex, bus terminus and so on is instrumental in the emerging form of encroachments.

\section{Edges}

Edges as elements are physical manifestations of the plot line. For the edges, a variety of physical manifestations are observed such as compound wall, level 
differences, etc. Compound walls or level differences have elementary property as the deadness of the edges.

Cities are created by a decision-making process that goes on continuously, day after day (Barnett 1974). The individual elements of the built environment and open spaces in the public realm influence and are influenced by other elements in the close vicinity. These interactions bring about trivial changes in the state of the elements and their elementary properties over a period of time. The changes in the elements and their properties can be observed at various temporal scales (daily, weekly, monthly, and yearly and so on).

\section{Emergent Properties of the Public Realm}

In complexity theory, $P$ is an emergent property of the system $S$ when $S$ is composed of elements $\left\{e_{1} \ldots e_{n}\right\}$ and our best micro knowledge of the elements does not attribute to them the property of producing $P$ (Gaus 2011). An emergent property can be defined as "a property of an assemblage that could not be predicted by examining the components individually" (Szabo and Teo 2013). The elementary properties of elements acting concurrently in the public realm at a given time have the capability of inducing newer properties of the public realm as a whole termed as emergent properties. In this study, the emergent properties of the public realm we intend to observe are EEEP and DEEP. This newer property is an emergent property (encouraging or discouraging encroachments) of the formal physical environment, instrumental in the emerging form of encroachments (Patil and Dongre 2013). EEEP and DEEP are instrumental in the emerging form of encroachments in the public realm.

An important feature of emergent properties is that the macro property $P$ emerges from a wide variety of values for $\left\{e_{1} \ldots e_{n}\right\}$. That is, if $P$ is an emergent property of $S$, there are many states of the micro elements $\left\{e_{1} \ldots e_{n}\right\}$ that produce $P$ (Gaus 2011). However, trivial changes in the state of elements and their elementary properties can bring about tremendous changes in the public realm over a period of time. The feed-back processes based on the continuous interaction of elementary properties maintains the public realm under continuous change. The change is generated because of the changing state of elements and their elementary properties. EEEP and DEEP of the public realm also change with time as it is a function of elementary properties acting concurrently. Because emergent properties may have undesired and unpredictable effects and consequences, and unpredictable systems are less credible and difficult to manage, techniques for the identification and validation of emergent properties pose an interesting challenge (Szabo and Teo 2013). On various temporal scales the public realm as a system can produce surprising levels of EEEP and DEEP. A computational model for experimenting with EEEP and DEEP of the public realm can provide an opportunity to observe the same. Experiments based on the computational model provide better insight into the emergence of encroachments in the public realm. 


\section{Parameters for Emergent Properties of the Public Realm: EEEP and DEEP}

Patil and Dongre (2013) state that the elements and structure of the formal physical environment have individual properties. While acting concurrently, they induce newer properties in the urban environment, which is encouraging or discouraging for encroachments. Based on this, the parameters for EEEP and DEEP are identified as elementary properties of individual elements of the public realm and are stated in Table 1. Elementary properties are under continuous change over a period of time and the respective change is shown in Table 2. These changes in the state of elementary properties are characterized by the feedback process, as the output of one interaction acts as input for another. Jervis (1998) and Ramalingam et al. (2008) state that feedback can be amplifying, or positive, such that a change in a particular direction or of a particular kind leads to reinforcing the pressures which lead to escalating a change in the system. Feedback can also be damping, or negative, such that the change triggers the forces that counteract the initial change and returns the system to the starting position, thereby tending to decrease deviation in the system (Ramalingam et al. 2008). Putting it another way, positive (reinforcing) feedback drives change, and negative (balancing, moderating, or dampening) feedback maintains stability in a system (Mitleton-Kelly 2003). Duarte et al. (2006) note that these laws, which are constantly applied in everyday life, form a dynamic set of rules that actuate in a bottom-up fashion to shape the urban tissue. The interactions of various elementary properties of elements are part of amplifying and dampening feedback processes in the public realm. This can be understood by an example as follows. In the public realm, due to mutual interaction with time, the degree of sense of ownership for a forecourt can be enhanced by a higher degree of exposure for adjacent activity. This enhanced sense of ownership can further enhance the degree of exposure for adjacent activity. This can be considered as amplifying feedback. The dampening feedback can also be understood in an exactly opposite manner.

Table 1 Elements, elementary properties, and emergent properties of the public realm

\begin{tabular}{|c|c|c|}
\hline $\begin{array}{l}\text { Elements of the } \\
\text { public realm }\end{array}$ & $\begin{array}{l}\text { Elementary } \\
\text { properties of } \\
\text { the elements }\end{array}$ & $\begin{array}{l}\text { Emergent } \\
\text { properties }\end{array}$ \\
\hline Adjacent activities & $\begin{array}{l}\text { Degree of exposure required }(p) \\
\text { Degree of spill over }(q) \\
\text { Supportiveness for } \\
\quad \text { complimentary activities }(r) \\
\text { Supportiveness for contrasting } \\
\text { activities }(s)\end{array}$ & \multirow[t]{5}{*}{$\begin{array}{l}\text { Elements and their elementary properties acting } \\
\text { concurrently leads to emergent properties- } \\
\text { Encouraging Encroachments Emergent } \\
\text { Property }(E E E P) \text {, and Discouraging } \\
\text { Encroachments Emergent Property }(D E E P) \text {. } \\
\text { The varying blend of EEEP and } D E E P \\
\text { influences the emerging form of } \\
\text { encroachments }\end{array}$} \\
\hline Open spaces & $\begin{array}{l}\text { Evenness of ground surface }(t) \\
\text { Freedom of } \\
\text { accessibility }(u)\end{array}$ & \\
\hline Forecourt & Sense of ownership $(v)$ & \\
\hline Major function & Catalytic nature of function $(w)$ & \\
\hline Edges & Deadness of edges $(x)$ & \\
\hline
\end{tabular}


Table 2 Different states of the elementary properties with time

\begin{tabular}{|c|c|c|c|c|}
\hline $\begin{array}{l}\text { Elementary } \\
\text { properties }\end{array}$ & $\begin{array}{l}\text { Initial } \\
\text { state }\end{array}$ & $\begin{array}{l}\text { Consequent } \\
\text { states }\end{array}$ & $\begin{array}{l}\text { Change in } \\
\text { the state }\end{array}$ & Changes in the state \\
\hline$p$ & $p_{0}$ & $p_{1}, p_{2}, \ldots, p_{n}$ & $\Delta p$ & $\begin{array}{l}\left\{\Delta p_{1}, \Delta p_{2}, \ldots, \Delta p_{n}\right\} \text { are the changes in the state of }\left\{p_{i}\right\}_{i=0}^{n} \\
\quad \text { where } \Delta p_{i+1}=p_{i+1}-p_{i}, i=0,1,2, \ldots, n-1\end{array}$ \\
\hline$q$ & $q_{0}$ & $q_{1}, q_{2}, \ldots, q_{n}$ & $\Delta q$ & $\begin{array}{l}\left\{\Delta q_{1}, \Delta q_{2}, \ldots, \Delta q_{n}\right\} \text { are the changes in the state of }\left\{q_{i}\right\}_{i=0}^{n} \\
\quad \text { where } \Delta q_{i+1}=q_{i+1}-q_{i}, i=0,1,2, \ldots, n-1\end{array}$ \\
\hline$r$ & $r_{0}$ & $r_{1}, r_{2}, \ldots, r_{n}$ & $\Delta r$ & $\begin{array}{l}\left\{\Delta r_{1}, \Delta r_{2}, \ldots, \Delta r_{n}\right\} \text { are the changes in the state of }\left\{r_{i}\right\}_{i=0}^{n} \\
\quad \text { where } \Delta r_{i+1}=r_{i+1}-r_{i}, i=0,1,2, \ldots, n-1\end{array}$ \\
\hline$s$ & $s_{O}$ & $s_{1}, s_{2}, \ldots, s_{n}$ & $\Delta s$ & $\begin{array}{l}\left\{\Delta s_{1}, \Delta s_{2}, \ldots, \Delta s_{n}\right\} \text { are the changes in the state of }\left\{s_{i}\right\}_{i=0}^{n} \\
\quad \text { where } \Delta s_{i+1}=s_{i+1}-s_{i}, i=0,1,2, \ldots, n-1\end{array}$ \\
\hline$t$ & $t_{o}$ & $t_{1}, t_{2}, \ldots, t_{n}$ & $\Delta t$ & $\begin{array}{l}\left\{\Delta t_{1}, \Delta t_{2}, \ldots, \Delta t_{n}\right\} \text { are the changes in the state of }\left\{t_{i}\right\}_{i=0}^{n} \\
\quad \text { where } \Delta t_{i+1}=t_{i+1}-t_{i}, i=0,1,2, \ldots, n-1\end{array}$ \\
\hline$u$ & $u_{O}$ & $u_{1}, u_{2}, \ldots, u_{n}$ & $\Delta u$ & $\begin{array}{l}\left\{\Delta u_{1}, \Delta u_{2}, \ldots, \Delta u_{n}\right\} \text { are the changes in the state of }\left\{u_{i}\right\}_{i=0}^{n} \\
\quad \text { where } \Delta u_{i+1}=u_{i+1}-u_{i}, i=0,1,2, \ldots, n-1\end{array}$ \\
\hline$v$ & $v_{0}$ & $v_{1}, v_{2}, \ldots, v_{n}$ & $\Delta v$ & $\begin{array}{l}\left\{\Delta v_{1}, \Delta v_{2}, \ldots, \Delta v_{n}\right\} \text { are the changes in the state of }\left\{v_{i}\right\}_{i=0}^{n} \\
\quad \text { where } \Delta v_{i+1}=v_{i+1}-v_{i}, i=0,1,2, \ldots, n-1\end{array}$ \\
\hline$w$ & $w_{O}$ & $w_{1}, w_{2}, \ldots, w_{n}$ & $\Delta w$ & $\begin{array}{l}\left\{\Delta w_{1}, \Delta w_{2}, \ldots, \Delta w_{n}\right\} \text { are the changes in the state of }\left\{w_{i}\right\}_{i=0}^{n} \\
\quad \text { where } \Delta w_{i+1}=w_{i+1}-w_{i}, i=0,1,2, \ldots, n-1\end{array}$ \\
\hline$x$ & $x_{0}$ & $x_{1}, x_{2}, \ldots, x_{n}$ & $\Delta x$ & $\begin{array}{l}\left\{\Delta x_{1}, \Delta x_{2}, \ldots, \Delta x_{n}\right\} \text { are the changes in the state of }\left\{x_{i}\right\}_{i=0}^{n} \\
\quad \text { where } \Delta p_{i+1}=p_{i+1}-p_{i}, i=0,1,2, \ldots, n-1\end{array}$ \\
\hline
\end{tabular}

Table 3 Interaction of elementary properties in the public realm

\begin{tabular}{lrrrrrrrrr}
\hline Elementary properties & $p_{i-1}$ & $q_{i-1}$ & $r_{i-1}$ & $s_{i-1}$ & $t_{i-1}$ & $u_{i-1}$ & $v_{i-1}$ & $w_{i-1}$ & $x_{i-1}$ \\
\hline$p_{i}$ & $\mathrm{x}$ & 0 & 0 & 0 & 0 & 0 & 0 & 0 & -1 \\
$q_{i}$ & 1 & $\mathrm{x}$ & 1 & -1 & 1 & -1 & 1 & 0 & 0 \\
$r_{i}$ & -1 & -1 & $\mathrm{x}$ & -1 & 1 & 1 & -1 & 0 & 1 \\
$s_{i}$ & -1 & -1 & -1 & $\mathrm{x}$ & 1 & 1 & -1 & 0 & 1 \\
$t_{i}$ & 0 & 1 & 1 & 0 & $\mathrm{x}$ & 0 & 1 & 0 & 0 \\
$u_{i}$ & 1 & 0 & 0 & 1 & 1 & $\mathrm{x}$ & 1 & 0 & 0 \\
$v_{i}$ & 1 & 1 & -1 & -1 & 1 & -1 & $\mathrm{x}$ & 0 & -1 \\
$w_{i}$ & 0 & 0 & 0 & 0 & 0 & 1 & 0 & $\mathrm{x}$ & 0 \\
$x_{i}$ & -1 & 0 & 0 & 0 & 0 & 0 & -1 & 0 & $\mathrm{x}$ \\
\hline
\end{tabular}

$\mathrm{x}$, no interaction; 0, non-significant interaction; 1 , amplifying interaction; -1 , dampening interaction

The interactions amongst the elementary properties that bring about changes in their states are identified under the categories: no interactions, the non-significant interactions, the amplifying interactions, and the dampening interactions, in Table 3.

\section{Meaningful Relationships for Feedback Processes in the Public Realm}

To determine the change in the state of an elementary property in one unit of time, we assume an interaction constant as $k$ in correspondence with the cumulative change in urban environment over the period of 1 year. For the amplifying 
interactions indicated as ' 1 ' in Table 3 , the interaction constant is $+k$. Amplification of the elementary property under consideration is the function of influenced property, influencing property, and interaction constant $+k$. For the dampening interactions indicated as ' -1 ' in Table 3 , the interaction constant is $-k$. Dampening of the elementary property under consideration is the function of influenced property, influencing property, and the interaction constant $-k$. The non-significant interactions are omitted to develop meaningful relationships of feedback processes in the public realm to simplify the agent-based model. Based on the amplifying and dampening one to one interactions mentioned in Table 3 and assuming interaction constant $+k$ and $-k$ respectively, meaningful relationships can be derived which determine the change in elementary property due to the mutual interactions leading to feedback processes as mentioned in Table 4.

The macro-level properties can be measured either as an aggregation of all the states of the system sub-components, or by observing the overall system behaviour and trends (Szabo and Teo 2013). In his System of Logic, Mill proposes three features of an emergent property $P$-(i) $P$ is not the sum of $\left\{e_{1} \ldots e_{n}\right\}$; (ii) $P$ is of an entirely different character than $\left\{e_{1} \ldots e_{n}\right\}$; (iii) $P$ cannot be predicted or deduced from the behavior of the members of $\left\{e_{1} \ldots e_{n}\right\}$ considered independently (i.e., apart from their interactions in $S$ ) (Gaus 2011). Owing to the above statements, the emergent properties of public realm EEEP and DEEP can be derived as the mean of

Table 4 Meaningful relationships for feedback processes in the public realm

\begin{tabular}{|c|c|}
\hline $\begin{array}{l}\text { Elementary } \\
\text { properties }\end{array}$ & Relationships for feedback processes \\
\hline$p$ & $\begin{array}{l}p_{i}-p_{i-1}=\Delta p_{i} \text {, then } p_{i}=p_{i-1}+\Delta p_{i}, \text { where } \Delta p_{i}=-k x_{i-1}, \text { so we have } p_{i}=p_{i-1} \\
\quad+\left(-k x_{i-1}\right) \text { i.e. } p_{i}=p_{i-1}-k x_{i-1}\end{array}$ \\
\hline$q$ & $\begin{array}{l}q_{i}-q_{i-1}=\Delta q_{i}, \text { then } q_{i}=q_{i-1}+q \text {, where } \Delta q_{i}=k p_{i-1}+k r_{i-1}-k s_{i-1}+k t_{i-1} \\
-k u_{i-1}+k v_{i-1}, \text { so we have } q_{i}=q_{i-1}+\left(k p_{i-1}+k r_{i-1}-k s_{i-1}+k t_{i-1}-\right. \\
\left.k u_{i-1}+k v_{i-1}\right)\end{array}$ \\
\hline$r$ & $\begin{array}{l}r_{i}-r_{i-1}=\Delta r_{i}, \text { then } r_{i}=r_{i-1}+\Delta r_{i}, \text { where } \Delta r_{i}=k t_{i-1}+k u_{i-1}+k x_{i-1}-k p_{i-1} \\
\quad-k q_{i-1}-k s_{i-1}-k v_{i-1}, \text { so we have } r_{i}=r_{i-1}+\left(k t_{i-1}+k u_{i-1}+k x_{i-1}-k p_{i-1}\right. \\
\left.\quad-k q_{i-1}-k s_{i-1}-k v_{i-1}\right)\end{array}$ \\
\hline$s$ & $\begin{array}{l}s_{i}-s_{i-1}=\Delta s_{i}, \text { then } s_{i}=s_{i-1}+\Delta s_{i}, \text { where } \Delta s_{i}=k t_{i-1}+k u_{i-1}+k x_{i-1}-k p_{i-1} \\
\quad-k q_{i-1}-k r_{i-1}-k v_{i-1}, \text { so we have } s_{i}=s_{i-1}+\left(k t_{i-1}+k u_{i-1}+k x_{i-1}-k p_{i-1}\right. \\
\left.\quad-k q_{i-1}-k r_{i-1}-k v_{i-1}\right)\end{array}$ \\
\hline$t$ & $\begin{array}{l}t_{i}-t_{i-1}=\Delta t_{i}, \text { then } t_{i}=t_{i-1}+\Delta t_{i}, \text { where } \Delta t_{i}=k q_{i-1}+k r_{i-1}+k v_{i-1} \\
\quad \text { so we have } t_{i}=t_{i-1}+\left(k q_{i-1}+k r_{i-1}+k v_{i-1}\right)\end{array}$ \\
\hline$u$ & $\begin{array}{l}u_{i}-u_{i-1}=\Delta u_{i} \text {, then } u_{i}=u_{i-1}+\Delta u_{i}, \text { where } \Delta u_{i}=k p_{i-1}+k s_{i-1}+k t_{i-1}+k v_{i-1} \\
\quad \text { so we have } u_{i}=u_{i-1}+\left(k p_{i-1}+k s_{i-1}+k t_{i-1}+k v_{i-1}\right)\end{array}$ \\
\hline$v$ & $\begin{array}{l}v_{i}-v_{i-1}=\Delta v_{i}, \text { then } v_{i}=v_{i-1}+\Delta v_{i}, \text { where } \Delta v_{i}=k p_{i-1}+k q_{i-1}-k r_{i-1} \\
-k s_{i-1}+k t_{i-1}-k u_{i-1}-k x_{i-1}, \text { so we have } v_{i}=v_{i-1}+\left(k p_{i-1}+k q_{i-1}-k r_{i-1}\right. \\
\left.-k s_{i-1}+k t_{i-1}-k u_{i-1}-k x_{i-1}\right)\end{array}$ \\
\hline$w$ & $\begin{array}{l}w_{i}-w_{i-1}=\Delta w_{i} \text {, then } w_{i}=w_{i-1}+\Delta w_{i}, \text { where } \Delta w_{i}=k u_{i-1} \\
\quad \text { so we have } w_{i}=w_{i-1}+k u_{i-1}\end{array}$ \\
\hline$x$ & $\begin{array}{l}x_{i}-x_{i-1}=\Delta x_{i} \text {, then } x_{i}=x_{i-1}+\Delta x_{i} \text {, where } \Delta x_{i}=-k p_{i-1}-k v_{i-1} \\
\quad \text { so we have } x_{i}=x_{i-1}+\left(k p_{i-1}-k v_{i-1}\right) \text { i.e. } x_{i}=x_{i-1}-k p_{i-1}-k v_{i-1}\end{array}$ \\
\hline
\end{tabular}


all elementary property's role in encouraging and discouraging encroachments respectively (Tables 5,6 ).

With reference to Table 5 and 6, the relationship of EEEP and DEEP with elementary properties can be stated as follows,

EEEP - Encouraging Encroachments Emergent

Property be $\left\{E E E P_{0}, E E E P_{1}, E E E P_{2} \ldots, E E E P_{n}\right\}$

$$
E_{E E P_{i}}=\left(\frac{1}{p_{i}}+\frac{1}{q_{i}}+\frac{1}{r_{i}}+s_{i}+t_{i}+u_{i}+\frac{1}{v_{i}}+w_{i}+x_{i}\right) / 9
$$

$D E E P$ - Discouraging Encroachments Emergent Property be $\left\{D E E P_{0}, D E E P_{1}, D E E P_{2}, \ldots, D E E P_{n}\right\}$

Table 5 Cluster level variables for EEEP

Determinants encouraging encroachments (Patil and Dongre 2013)

Adjacent activities with the lower need of exposure

Adjacent activities with the lower need of spillover

Adjacent activities with lower supportiveness for complementary activities

Adjacent activities with higher supportiveness for contrasting activities

Open spaces with considerably even ground surface Open spaces with higher freedom of accessibility

The lower sense of ownership of the forecourt

The higher catalytic nature of major functions in the vicinity

The higher deadness of edges
Role in EEEP

The lower value of $p$ contributes higher i.e., $1 / p$ The lower value of $q$ contributes higher i.e., $1 / q$ The lower value of $r$ contributes higher i.e., $1 / r$

The higher value of $s$ contributes higher i.e., $s$

The higher value of $t$ contributes higher i.e., $t$ The higher value of $u$ contributes higher i.e., $u$ The lower value of $v$ contributes higher i.e., $1 / v$ The higher value of $w$ contributes higher i.e. $w$ The higher value of $x$ contributes higher i.e., $x$

Table 6 Cluster level variables for DEEP

Determinants discouraging encroachments (Patil and Dongre 2013)

Adjacent activities with the higher need of exposure Adjacent activities with the higher need of spillover

Adjacent activities with the higher supportiveness for complementary activities

Adjacent activities with lower supportiveness for contrasting activities

Open spaces with considerably an uneven ground surface

Open spaces with lower freedom of accessibility

The Higher sense of ownership of the forecourt

The lower catalytic nature of major functions in the vicinity

The lower deadness of edges
Role in $D E E P$

The higher value of $p$ contributes higher i.e., $p$

The higher value of $q$ contributes higher i.e., $q$

The higher value of $r$ contributes higher i.e., $r$

The lower value of $s$ contributes higher i.e., $1 / s$

The lower value of $t$ contributes higher i.e., $1 / t$

The lower value of $u$ contributes higher i.e., $1 / u$ The higher value of $v$ contributes higher i.e., $v$

The lower value of $w$ contributes higher i.e., $1 / w$

The lower value of $x$ contributes higher i.e., $1 / x$ 


$$
D_{E E P}=\left(p_{i}+q_{i}+r_{i}+\frac{1}{s_{i}}+\frac{1}{t_{i}}+\frac{1}{u_{i}}+v_{i}+\frac{1}{w_{i}}+\frac{1}{x_{i}}\right) / 9
$$

The values of EEEP and DEEP derived form (1) and (2) have to be understood in relative terms. If the value of $E E E P$ is higher than $D E E P$, then it refers to emergent property of the public realm encouraging encroachments and increases probability of the public realm getting encroached. If the value of DEEP is higher than EEEP, then it refers to emergent property of the public realm discouraging encroachments and decreases the probability of the public realm being encroached.

\section{Quantifying Elementary Properties of Individual Elements of the Public Realm}

Micro-level properties are usually measured by observing the component states such as the collection of all variables and their values, of each system component (Szabo and Teo 2013). The elementary properties of the individual elements in the public realm are quantified on the basis of variation observed in the real world. They are quantified on an ordinal scale ranging from 0.1 to 0.9 for conducting experiments related to emergent properties EEEP and DEEP (Table 7).

\section{Emergent Properties of Public Realm (3.1) Model}

The fundamentals behind understanding different types of emergence lie in the assumption that in any component-based system there is a micro-level, the abstraction level of each individual component, and a macro-level, the abstraction of the composed model as a whole (Szabo and Teo 2013). In recent decades, computational models have been proposed as a way to assist us in understanding emergent phenomena (Symons 2008). Agent-based modeling is of great help in getting insight into complex systems. Agent-based modeling provides a toolkit for both discovering emergent behavior and understanding it in terms of interaction of components (Schank 2010). We try to formulate a simplified representation of the system using equations or a computer program that we can then manipulate and experiment on (to formulate a model means to design its assumptions and algorithms) (Railsback and Grimm 2011). We can achieve a deeper and more precise understanding of the phenomenon we wish to understand, explain and predict (Schank 2010). The public realm, as a complex system if modeled by means of agent-based modeling can offer better insight into the emergent properties of the public realm.

Mason, NetLogo, Repast, Swarm, etc. are some agent based modeling environments with a variety of features and merits. Mason is the overall best choice, and fit for the purpose of exploring complex adaptive systems, but requires a high level of programming experience. For simple models, and for people with little programming experience, NetLogo is highly recommended (Berryman 2008). NetLogo is best suited for its 3D and GIS capabilities. Berryman (2008) notes that Repast is the most complete platform, and has a comparatively good execution time 


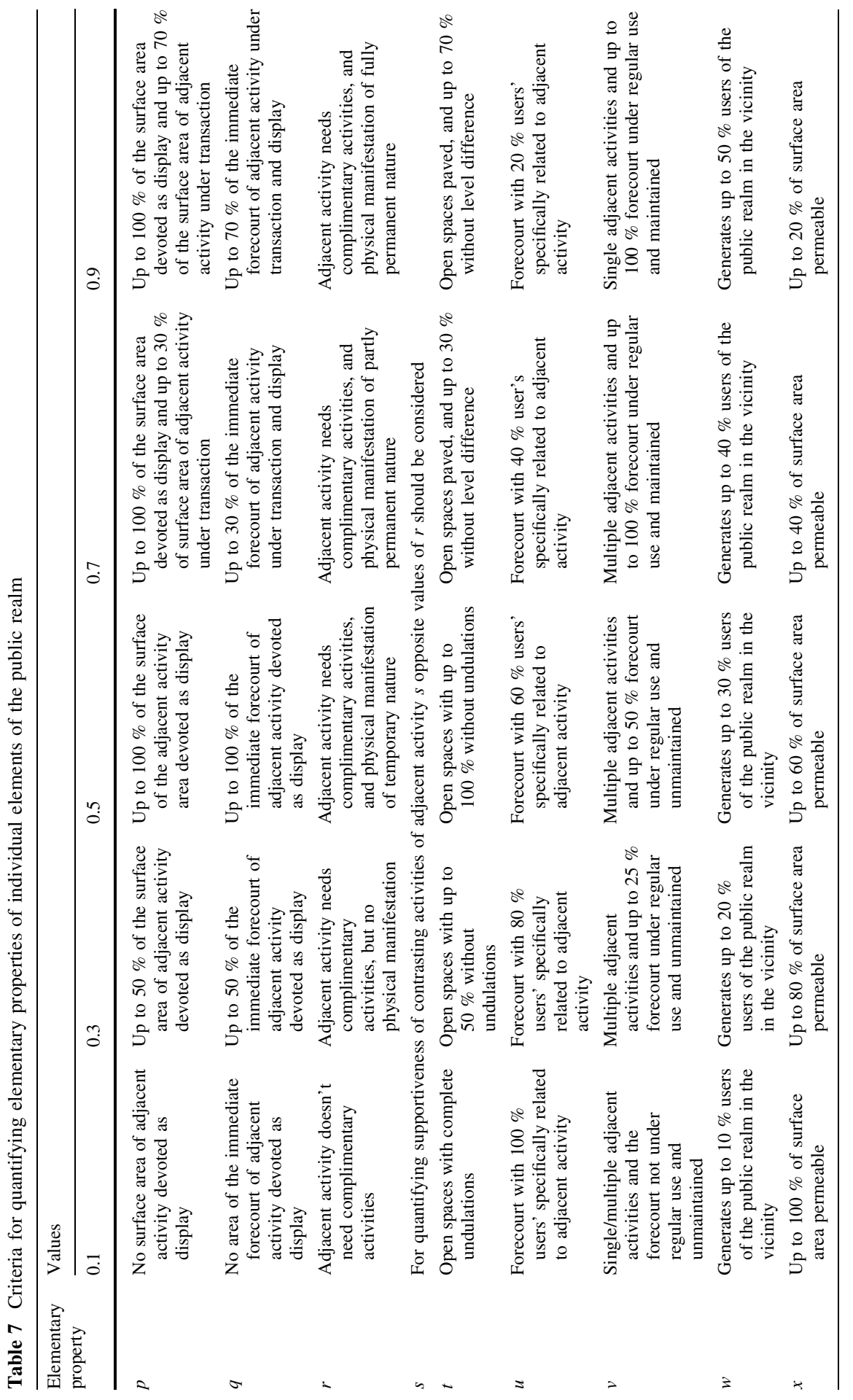


of simulations. It has poor documentation in places, and also some "average" software engineering design choices, but is overall the best ABM platform. Swarm is now looking relatively geriatric at the early age of about 10 years. Although still very usable by the expert, it is not designed specifically for social science applications, and is not well supported (Robertson 2005).

NetLogo provides a very accessible introduction to agent-based modeling (Robertson 2005). NetLogo is particularly well suited for modeling complex systems developing over time. Modelers can give instructions to hundreds or thousands of "agents" all operating independently. This makes it possible to explore the connection between the micro-level behavior of individuals and the macro-level patterns that emerge from their interaction (Wilensky 1999). NetLogo is optimized for modeling emergent bottom-up systems: local interactions between large (or small) populations of agents, governed by simple rules of mutual feedback can be efficiently modeled allowing the mind to wrap itself around a complex idea. Importantly, NetLogo disproves the assumption that emergent collective behavior implies some kind of centralized authority. The elucidation of this concept makes the program important to the study (and teaching) of architecture and urban design (Felsen et al. 2006). NetLogo was chosen based on its importance for applicability in the social sciences, urban design, 3D and GIS capabilities, and ease for beginners to author scientific models. The 3D and GIS capabilities would be of great help in expanding the model in the future at precinct or urban area level.

The computational model-Emergent Properties of Public Realm 3.1 (EPPR 3.1) was developed in Net Logo 4.1.3. The model was designed to explore questions about emergent properties (EEEP and DEEP) of the public realm in the urban environment. How do the feedback processes in the interaction of elementary properties of individual elements of the public realm leads to the emergent properties i.e. EEEP and $D E E P$ ? How does variability in individual properties and interaction constant (amplifying and dampening) affect the emergence of EEEP and DEEP?

The model has only one entity: square patches representing individual elements of the public realm of the urban environment. The patches make up a square grid of the public realm of $3 \times 3$ patches. The patches are of four types-three patches (grey) representing adjacent activity, four patches (red) representing the forecourt, one patch (yellow) representing open spaces, one patch (green) representing major function in the vicinity and the interface between forecourt and open spaces is representing edges (Fig. 2). The proportion of these patches is similar to the commonly observed proportion in the real world. The state variables for the patches are defined as follows:

- Adjacent activity has four state variables: $p, q, r$, and $\mathrm{s}$,

- Open space has three state variables: $t, u$, and $x$,

- Forecourt has one state variable: $v$,

- Major function in the vicinity has one state variable: $w$.

Patch size is not specified because the model is generic. One tick is assumed to be a 1 week step in the simulation and the simulation lasts for 52 ticks (1 year). There is only one process in the model-changing state variables of patches. On each tick, each patch changes its respective state variables $(p, q, r, s, t, u, v, w$, and $x$ ) based on 


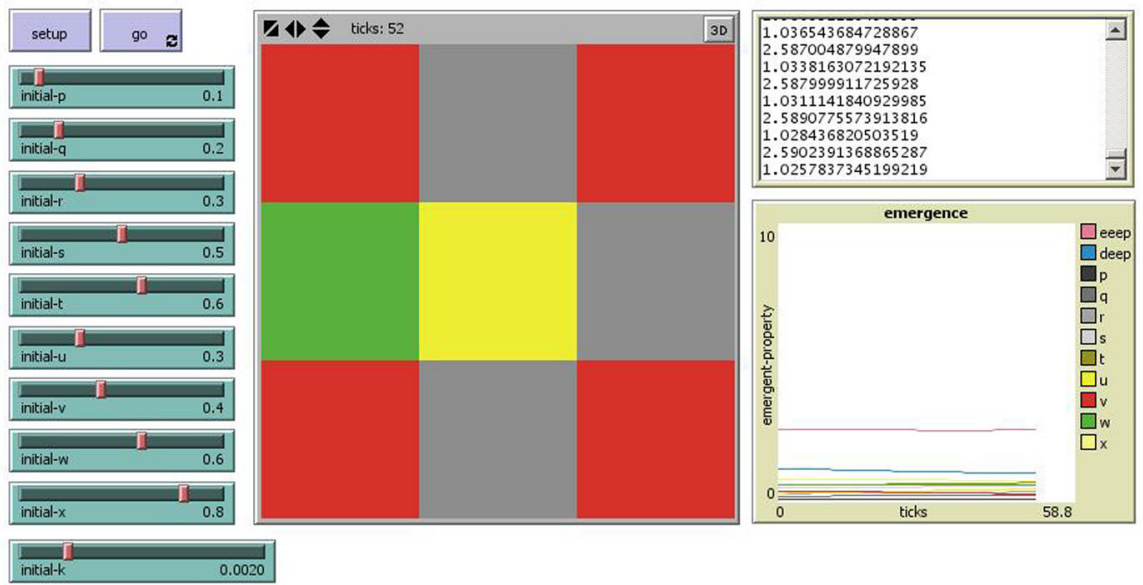

Fig. 2 Emergent Properties of the Public Realm (3.1) model in NetLogo 4.1.3. Computer rendering: Author

the interaction constant and elementary properties of surrounding individual elements resulting into the modified state variable.

To allow observation of emergent properties-EEEP and DEEP of the public realm, we defined a specific 'eeep' and 'deep' measure respectively, which is a function of $p, q, r, s, t, u, v, w$, and $x$ as elementary properties of elements of the public realm, computed based on Eqs. 1 and 2 in Sect. 5. The representative public realm is initialized when the model starts. The state variables of patches are set to initial value.

\section{Opportunities with EPPR (3.1) Model in NetLogo 4.1.3}

The model can aid urban designers in generation (decision making) of coherence at the smallest and the most important scale of the public realm in urban areas with respect to the emergence of encroachments. The model can compute emergent properties-EEEP and DEEP for any given individual case in time. The model can compute the constant changes in the elementary properties $(p, q, r, s, t$, $u, v, w$, and $x$ ) of the individual elements based on the feedback constant in time. The model can map the phase space of the public realm. The model can compute the above-mentioned output for every time step and export the same in.csv format. The same can be imported in other programs for detailed analysis. The model can compute the elementary properties and emergent properties of the public realm with different interaction constants in the range of $0.001-0.009$ with time. This range of the interaction constant from 0.001 to 0.009 was assumed in correspondence with the cumulative change over a period of a year ranging approximately from 5 to $50 \%$ respectively. The temporal scale and the interaction 
constant can be altered with convenience for experimental purposes. The model has the capability of running 410065408 combinations of interaction constants and parameters to compute elementary properties and emergent properties in time for a particular case.

\section{Public Realm Experiments Based on EPPR 3.1 in NetLogo 4.1.3}

The experiments for emergent properties of the public realm were conducted on EPPR 3.1 to explore the following:

- Behaviour of the public realm as a system and the variability of EEEP and $D E E P$ in the course of time.

- Variability in the emergence of EEEP and DEEP corresponding to the real world, with reference to the value of assumed interaction constant $k$ in the range of $0.001-0.009$.

To address the above-mentioned inquiries, the experiments for various cases were conducted in the following stages:

- Various cases representing encroached and non-encroached domains of the public realm were identified from Nagpur, Hyderabad, and Vijayawada in India. Three typical cases, Cases 1, 2, and 3 refer to the public realm in the real world with no encroachments, with encroachments, and with encroachments developed into a speciality market respectively.

- The nine elementary properties of the individual elements of the public realm in identified cases were quantified based on the criteria mentioned in Table 7. This allotted value for each elementary property was taken as the initial value.

- The initial value is taken as input for EPPR 3.1 and the public realm was simulated for assumed interaction constant $k$ ranging from 0.001 to 0.009 amounting to 9 runs for each case. The public realm was simulated for 52 ticks corresponding to approximately a 1 year span to observe the emergence of EEEP and DEEP.

\section{Typical Cases from Nagpur, India}

Nagpur is the winter capital of Maharashtra state in India. Apart from being a political centre it also acts as administrative, business and educational centre. The urban core named Sitabuldi was studied in detail and three cases were identified for the demonstration mentioned as follows:

- Case 1, Moonlight Studio is a famous photography studio, and also caters to the need for photography instruments and accessories. An important landmark and no encroachments are observed in the public realm adjoining it (Fig. 3a). 
- Case 2, Eternity Mall acts as a major function in itself and is strategically sited. It houses various shops and entertainment activities and acts as a crowd puller. The public realm adjoining it is dotted with encroachments (Fig. 3b).

- Case 3, Offices of Government Agencies with not much influx of visitors and close to the market place. Encroachments are observed in the public realm adjoining it. These encroachments with time have developed into a famous destination for purchasing used books. It is an informal market closely knit with the formal development (Fig. 3c).

\section{Typical Cases from Hyderabad, India}

Hyderabad is the capital of Andhra Pradesh in India. Apart from being a political centre it also acts as administrative, business and educational centre. Three cases were identified for the demonstration mentioned as follows:

- Case 1, Sagar Plaza, Abids is located in between Abids and Bank Street Road. It consists of Vishal Mega Mart and more commercial shops and offices. There are no encroachments observed in the front and surroundings of this building (Fig. 4a).

- Case 2, MPM Mall, Abids is a major commercial centre. General Post Office Headquarters is located exactly opposite to it. Encroachments are commonly observed around it (Fig. 4b).

- Case 3, Koti is one of the best-known commercial suburbs. It is famous as a book market. A wide variety of book shops are located here. Encroachments are observed in this domain (Fig. 4c).

Typical Cases from Vijayawada, India

Vijayawada is an important city of Andhra Pradesh in India. It acts as an administrative, business and educational centre. Three cases were identified for the demonstration mentioned as follows:

- Case 1, Big Bazaar Complex is spread over three floors and is a spot for shopping for household goods. There is wide scope for encroachment because it attracts a large number of people for shopping, and it is observed that there is no encroachment in front of this complex except 2-3 stalls maintained by the complex authorities (Fig. 5a).

- Case 2, Kalamandir Complex mainly features shopping related to clothes and jewellery. Due to the development of this structure a lot of street vendors and hawkers of all kinds are found at the entrance to this building. High levels of encroachment are found on either side of the street occupying most of the public realm (Fig. 5b).

- Case 3, Electronic Complex was a commercial complex built by the municipal authorities for all purposes. Over a period of time stilt parking for the complex started to get encroached slowly on the road side by small electronic shops (Fig. 5c). 

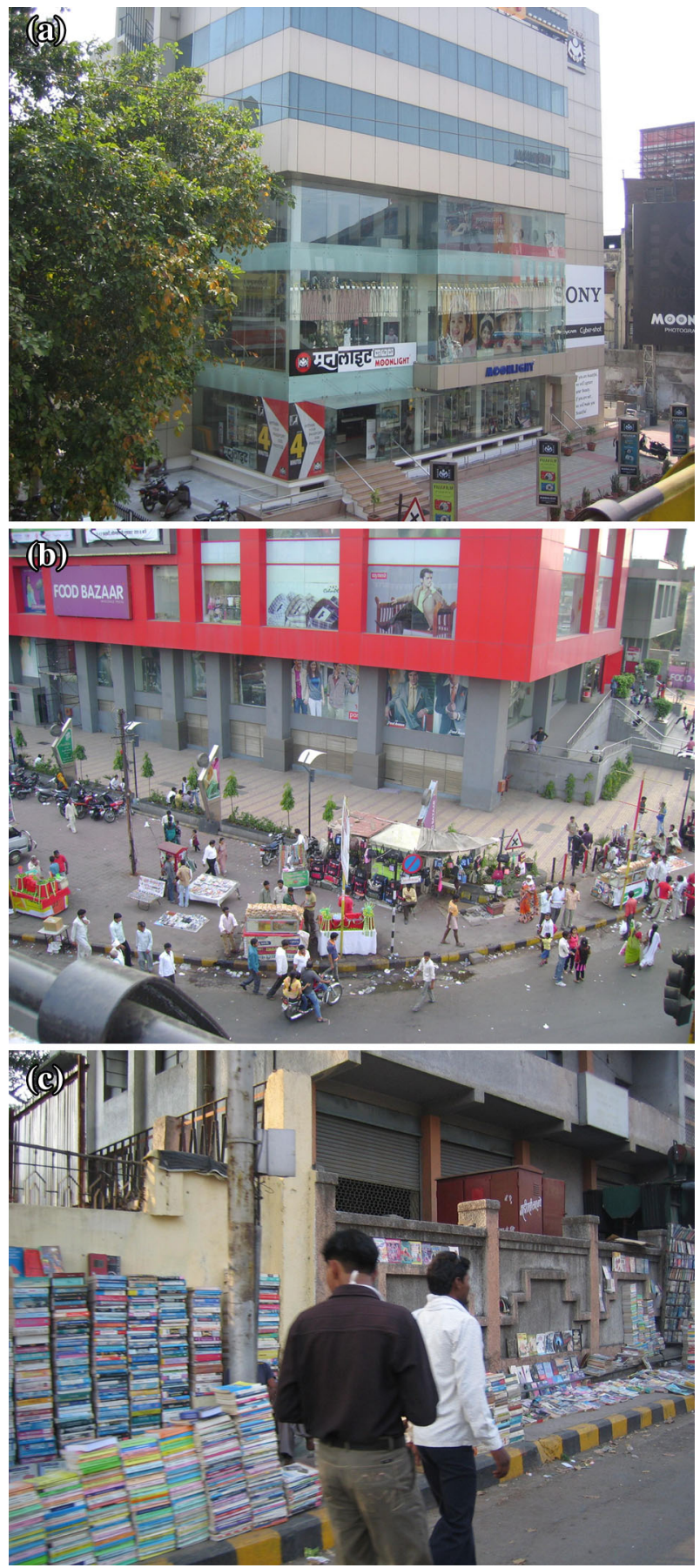

Fig. 3 a Identified case of the public realm in Nagpur-Case 1, Moonlight Studio, Sitabuldi. Photo: Author. b Identified case of the public realm in Nagpur - Case 2, Eternity Mall, Sitabuldi. Photo: Author. c Identified case of the public realm in Nagpur-Case 3, Office of Government agencies, Sitabuldi. Photo: Author 
Fig. 4 a Identified case of the public realm in HyderabadCase 1, Sagar Plaza, Abids. Photo: Author. b Identified case of the public realm in

Hyderabad-Case 2, MPM

Mall, Abids. Photo: Author.

c Identified case of the public realm in Hyderabad-Case 3, Koti. Photo: Author
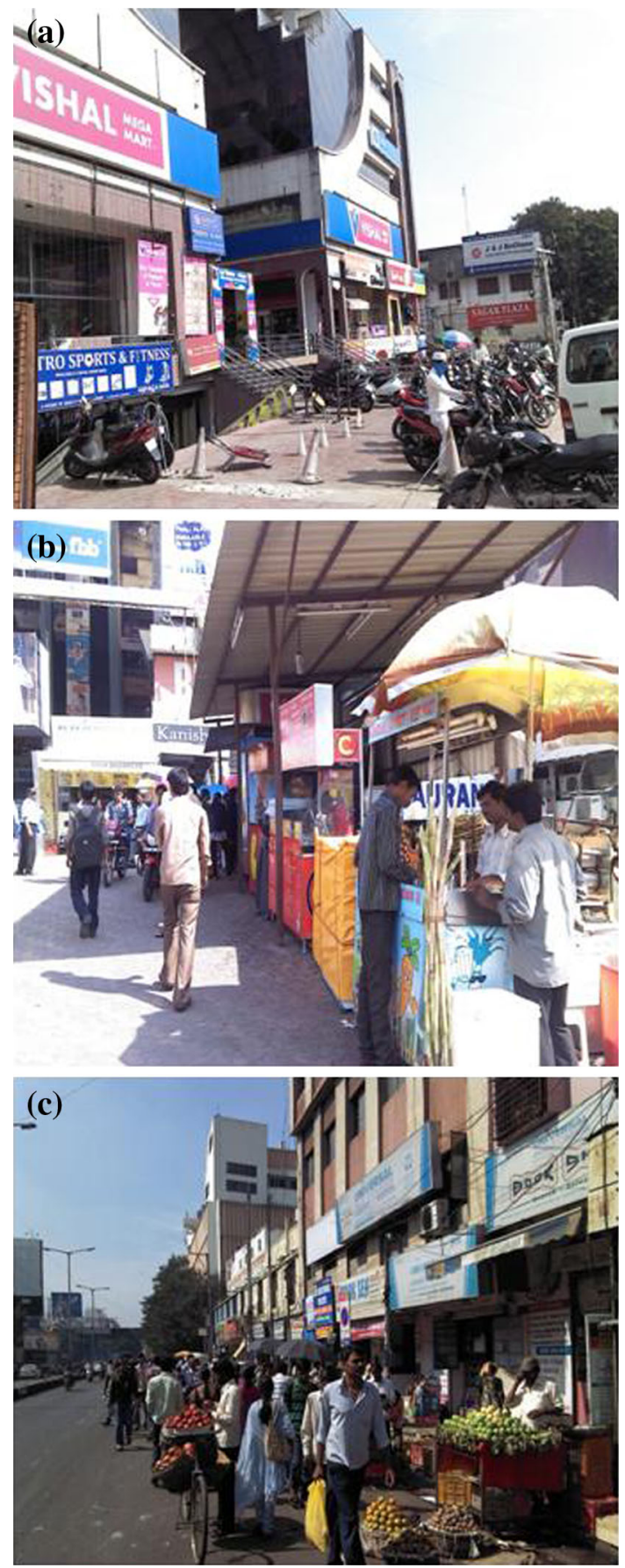

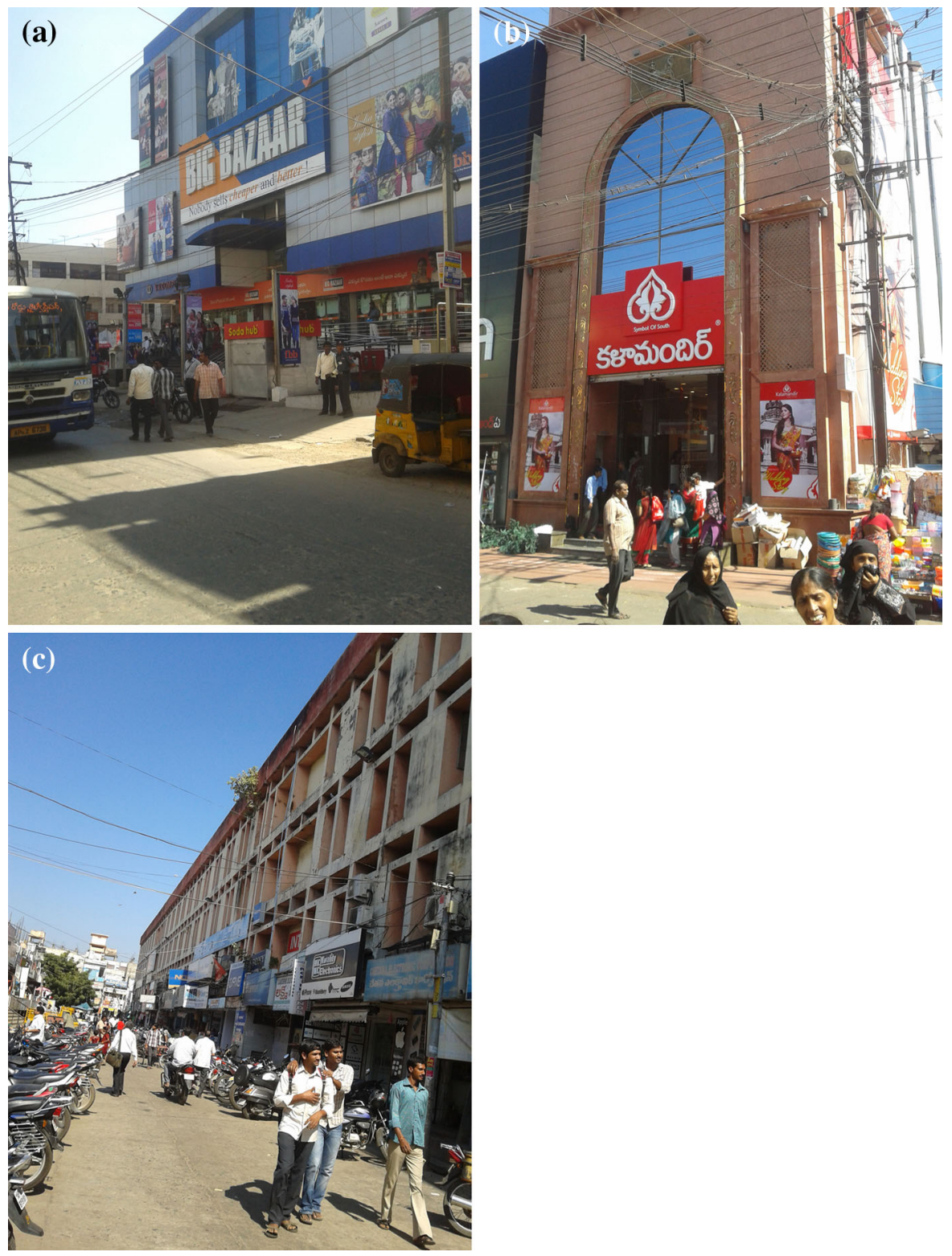

Fig. 5 a Identified case of the public realm in Vijayawada-Case 1, Big Bazaar Complex, Governorpeta. Photo: Author. b Identified case of the public realm in Vijayawada-Case 2, Kalamandir Complex, Governorpeta. Photo: Author. c Identified case of the public realm in Vijayawada-Case 3, Electronic Complex, Governorpeta. Photo: Author

Quantification of nine elementary properties of the individual elements of the public realm in identified cases based on Table 7 is mentioned in Table 8 for Nagpur, Hyderabad, and Vijayawada respectively. The identified cases were simulated using EPPR 3.1 and the emergent properties EEEP and DEEP with 
Table 8 Allotted values for the elementary properties for identified cases based on site observations

\begin{tabular}{|c|c|c|c|c|c|c|c|c|c|}
\hline \multirow{2}{*}{$\begin{array}{l}\text { Elementary properties } \\
\text { of elements }\end{array}$} & \multicolumn{3}{|l|}{ Nagpur } & \multicolumn{3}{|c|}{ Hyderabad } & \multicolumn{3}{|c|}{ Vijayawada } \\
\hline & Case 1 & Case 2 & Case 3 & Case 1 & Case 2 & Case 3 & Case 1 & Case 2 & Case 3 \\
\hline $\begin{array}{l}\text { Degree of exposure } \\
\text { required }(p)\end{array}$ & 0.7 & 0.3 & 0.1 & 0.5 & 0.3 & 0.9 & 0.5 & 0.7 & 0.9 \\
\hline Degree of spill over $(q)$ & 0.3 & 0.1 & 0.1 & 0.1 & 0.5 & 0.3 & 0.3 & 0.5 & 0.9 \\
\hline $\begin{array}{l}\text { Supportiveness for } \\
\text { complimentary } \\
\text { activities }(r)\end{array}$ & 0.3 & 0.3 & 0.1 & 0.7 & 0.5 & 0.1 & 0.7 & 0.1 & 0.3 \\
\hline $\begin{array}{l}\text { Supportiveness for } \\
\quad \text { contrasting activities }(s)\end{array}$ & 0.7 & 0.7 & 0.9 & 0.3 & 0.5 & 0.9 & 0.3 & 0.9 & 0.7 \\
\hline $\begin{array}{l}\text { Evenness of ground } \\
\text { surface }(t)\end{array}$ & 0.5 & 0.9 & 0.9 & 0.9 & 0.9 & 0.9 & 0.7 & 0.9 & 0.9 \\
\hline $\begin{array}{l}\text { Freedom of accessibility } \\
\quad(u)\end{array}$ & 0.7 & 0.9 & 0.9 & 0.3 & 0.5 & 0.7 & 0.5 & 0.7 & 0.5 \\
\hline Sense of ownership $(v)$ & 0.9 & 0.3 & 0.5 & 0.7 & 0.5 & 0.5 & 0.9 & 0.7 & 0.5 \\
\hline $\begin{array}{l}\text { Catalytic nature of } \\
\text { function }(w)\end{array}$ & 0.5 & 0.9 & 0.5 & 0.1 & 0.9 & 0.5 & 0.9 & 0.7 & 0.5 \\
\hline Deadness of edges $(x)$ & 0.7 & 0.7 & 0.9 & 0.7 & 0.5 & 0.5 & 0.3 & 0.1 & 0.1 \\
\hline
\end{tabular}

respect to time and various values of the interaction constant are represented in Figs. 6, 7, and 8. The mean of emergent properties EEEP and DEEP for cases with respect to various values of interaction constant is represented in Fig. 9.

\section{Discussions}

The observations through phase space mapping of identified cases is as follows-

\section{Nagpur}

- In Case 1-Moonlight Studio, EEEP raises gradually and DEEP falls gradually with time and increase in value of $k$. The difference between $E E E P$ and $D E E P$ increases with time and increase in value of $k$. It is observed that, mean of EEEP is higher than mean of DEEP which does not corresponds to the real world. However, the difference between them is small/negligible (Figs. 6, 9a).

- In Case 2-Eternity Mall, the rate of rise in EEEP increases with time and an increasing value of $k$, but decreases in later stages for the value of $k=0.007$, 0.008 , and 0.009. It is observed that the mean of EEEP is much higher than the mean of DEEP which corresponds to the real world. The mean of EEEP rises tremendously with an increase in the value of $k$, but variation in the mean of $D E E P$ is negligible. The mean of EEEP is approximately three times the mean of $D E E P$ at the value of $k=0.001$, but rises considerably up to approximately four times for the value of $k=0.009$ (Figs. 6, 9a).

- In Case 3-Offices of Government Agencies, EEEP decreases gradually with time for $k=0.001$ and 0.002 , decreases and increases gradually at later stages 

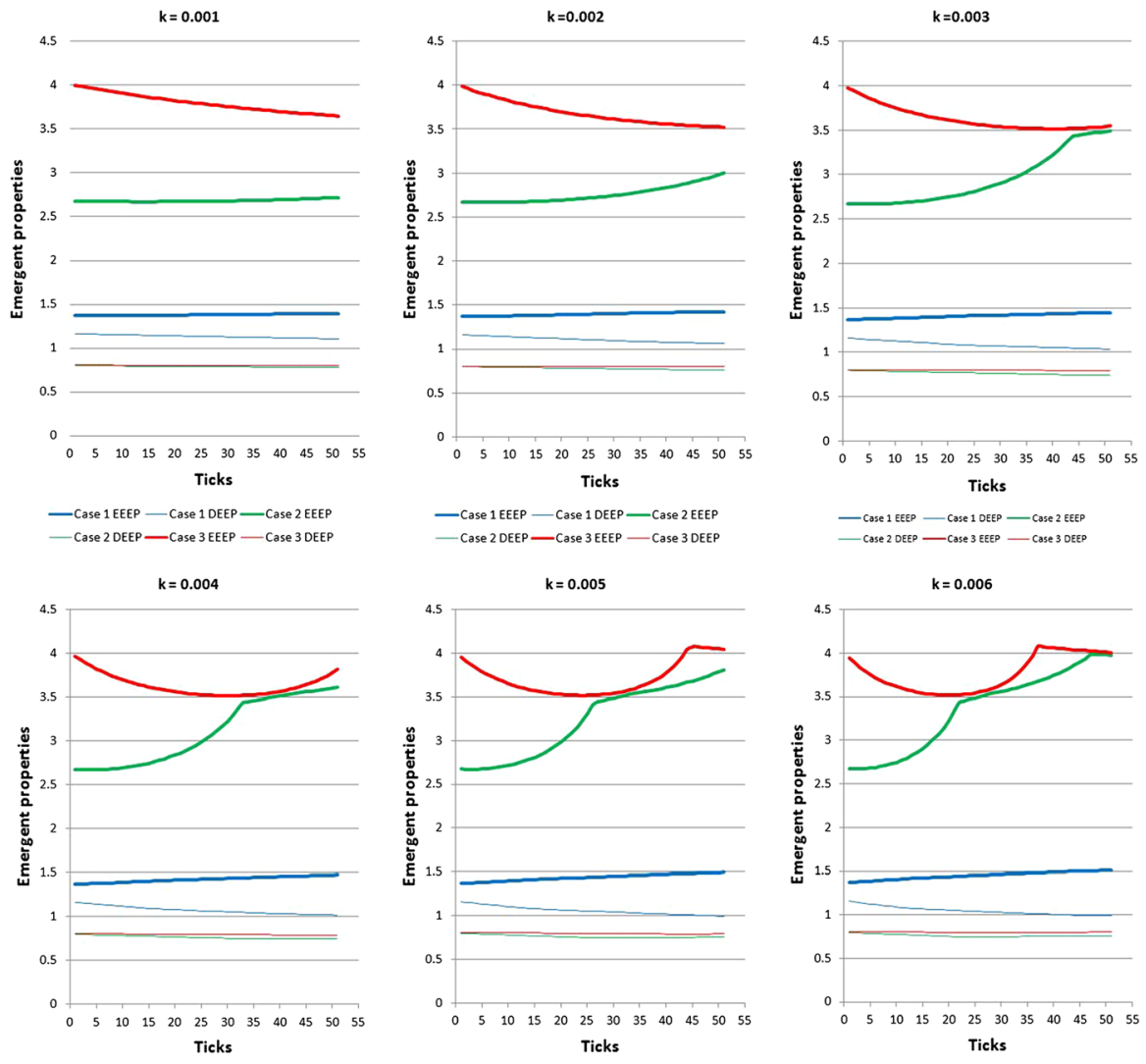

— Case 1 EEEP —Case 1 Degp —C Case 2 EEEP - Case 2 DEEP —Cose 3 EEg — Cose 3 DEEP

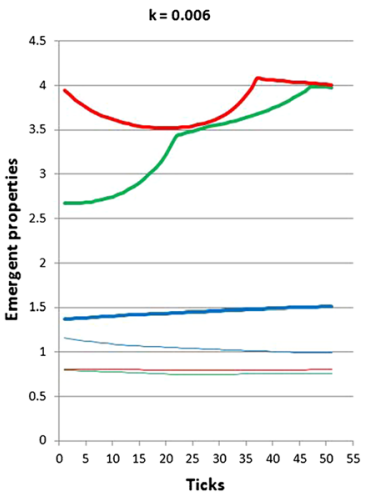

—Case 1 EeEP — Case 1 DeEP — Case 2 EeEp — Case 2 DeEp — Case 3 EeEP — Case 3 deEp
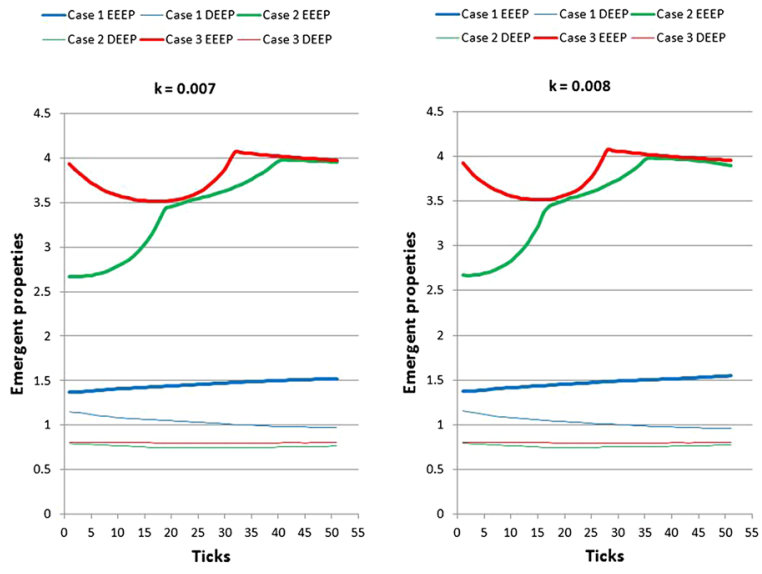

—Case 1 eEeP - Case 1 DeEP — Case 2 EeEP - Case 2 deEp —Case 3 EeEp — Case 3 deEp

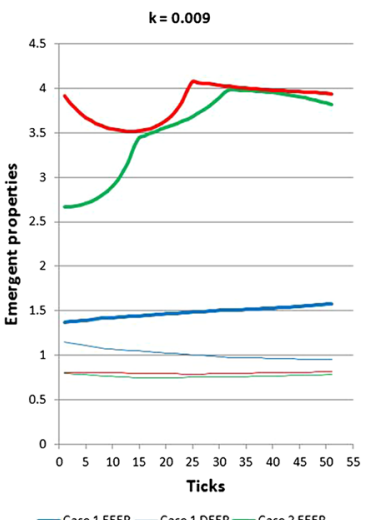

- Case 1 eeep - Case 1 deep - Case 2 eeep —Case 2 DeEp —Case 3 EeEP —Case 3 DeEp

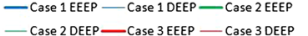

Fig. 6 Emergent properties of Case 1, Case 2, and Case 3 from Nagpur for value of $k=0.001-0.009$ in time. Computer rendering: Author 

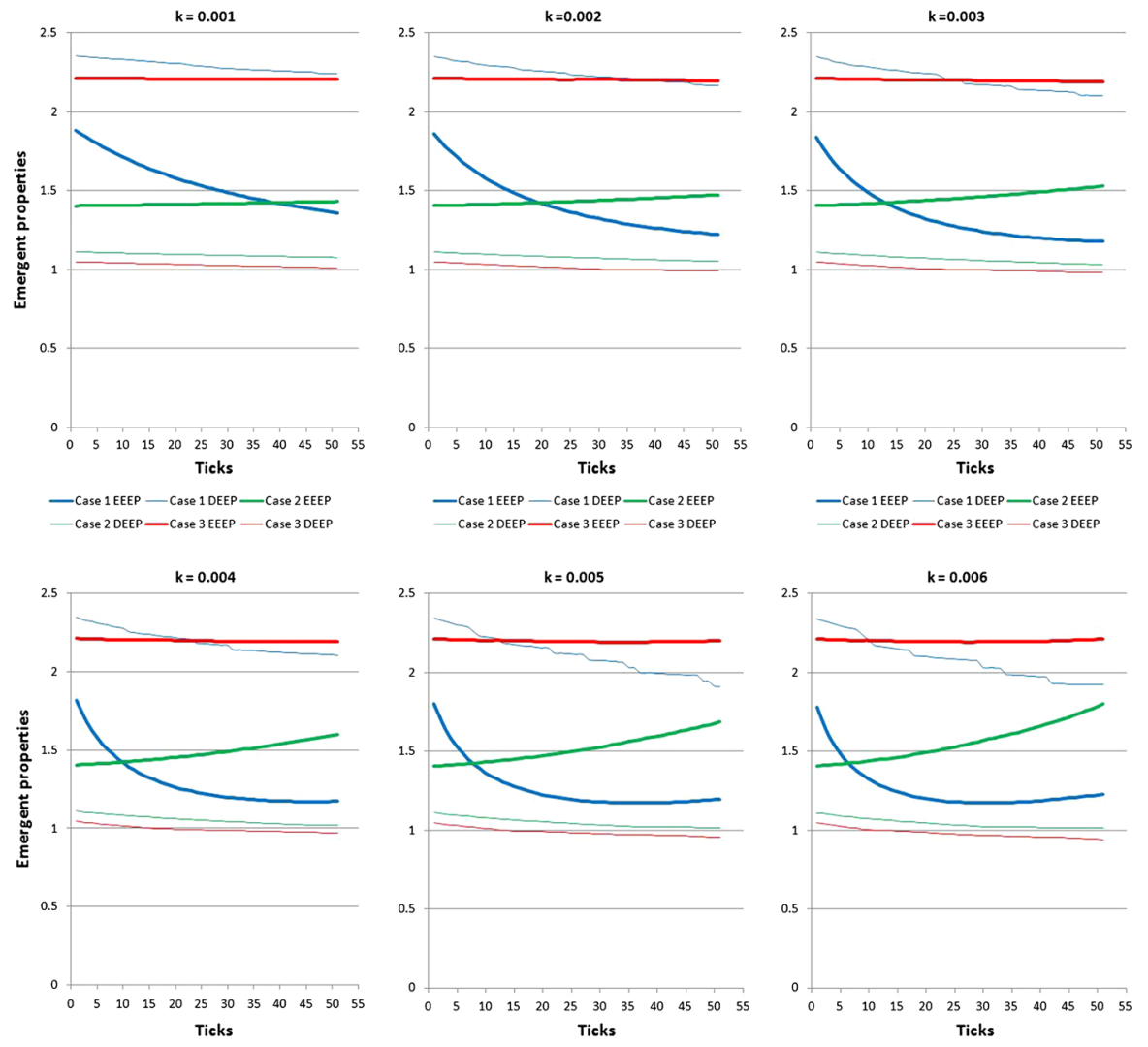

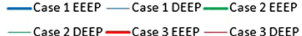

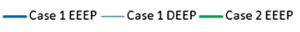

- Case 2 deEp - Case 3 EeEp - Case 3 deEp

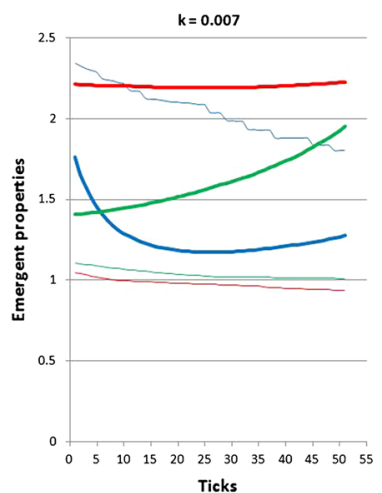

$k=0.008$
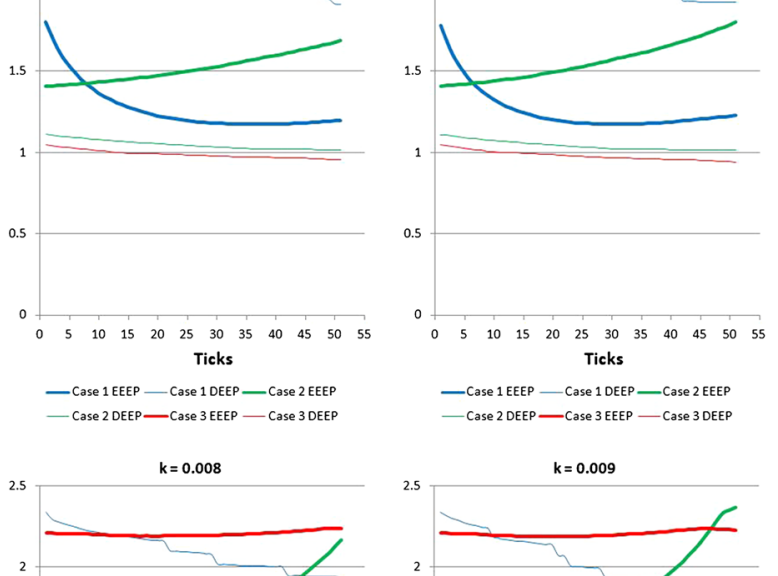

$$
\begin{aligned}
& \text {-Case } 1 \text { EEEP - Case } 1 \text { DEEP - Case } 2 \text { EEEP } \\
& \text { —Case } 2 \text { DeEP — Case } 3 \text { EeEP — Case } 3 \text { DeEp }
\end{aligned}
$$
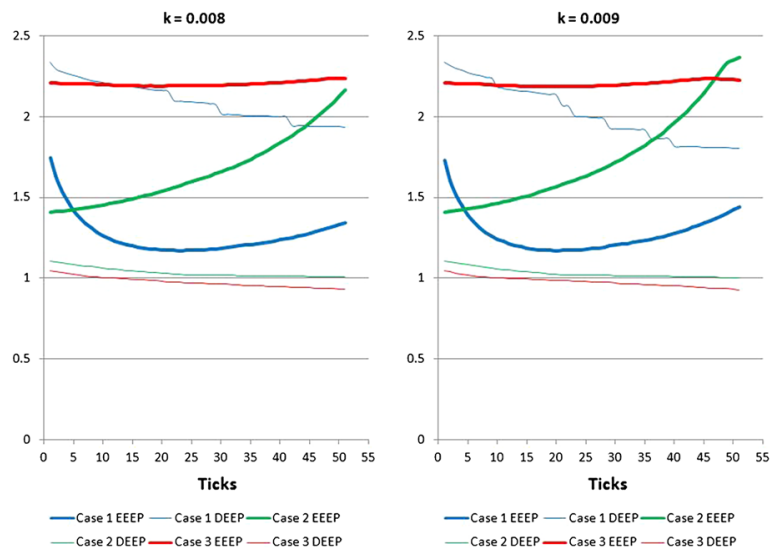

C Case 2 DEEP — Case 3 EEEP —C Case 3 DEEP

Fig. 7 Emergent properties of Case 1, Case 2, and Case 3 from Hyderabad for value of $k=0.001-0.009$ in time. Computer rendering: Author 

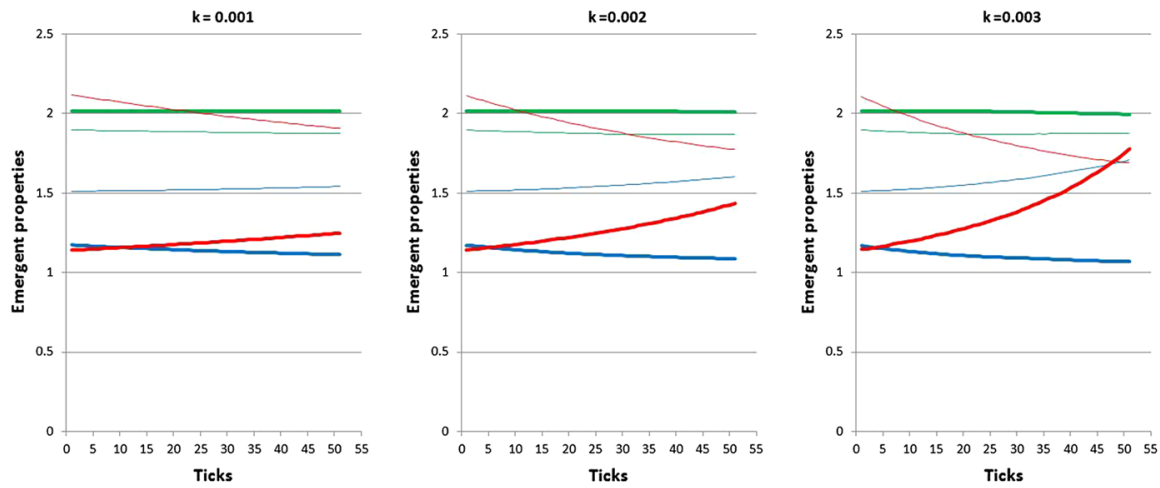

- Case 1 EeEP — Case 1 deEP — Case 2 EeEP - Case 2 Deep - Case 3 Eeep — Case 3 deep
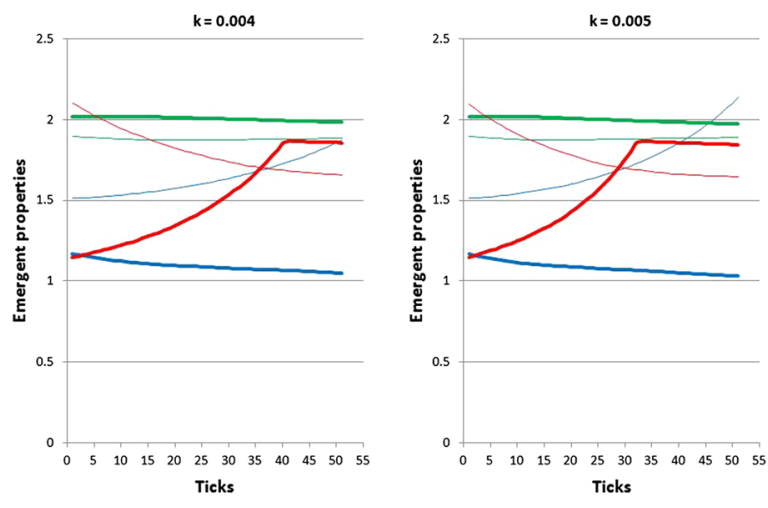

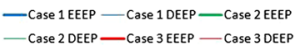

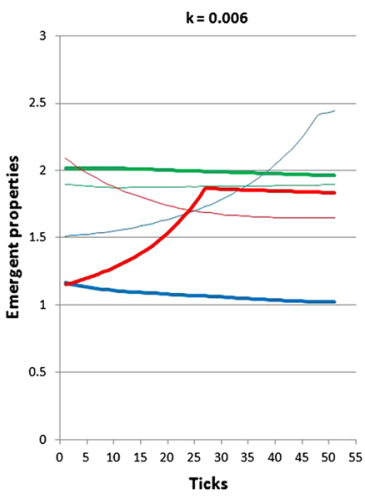

- Case 1 EeEP - Case 1 deep - Case 2 EeEP - Case 2 DeEP — Case 3 EeEP —Case 3 DeEP

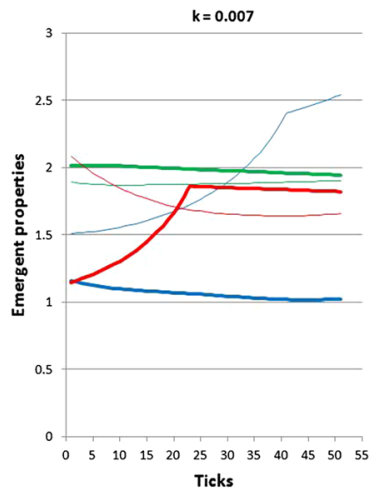

—Case 1 eeep - Case 1 Deep —Case 2 eeep - Case 2 DEEP — Case 3 EEEP — Case 3 DEEP

—Case 1 EeEP - Case 1 DeEP — Case 2 EeEP Case 2 DeEp —Case 3 eetp — Case 3 DeEP
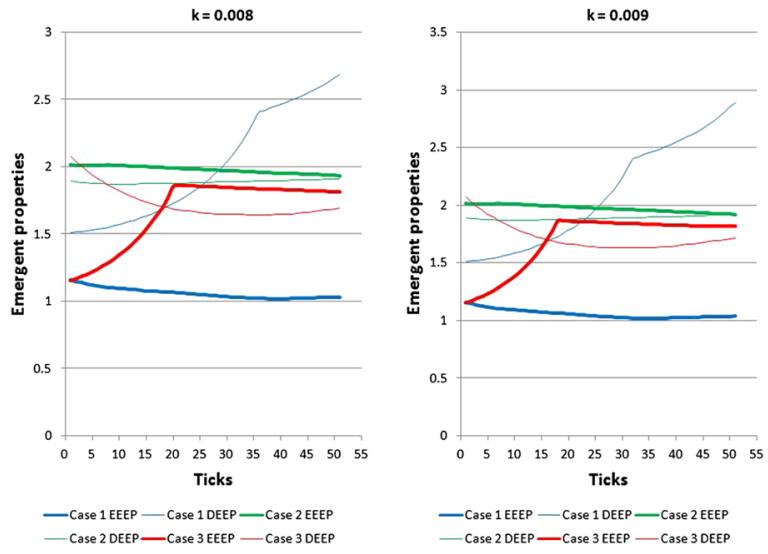

Fig. 8 Emergent properties of Case 1, Case 2, and Case 3 from Vijayawada for value of $k=0.001-0.009$ in time. Computer rendering: Author 

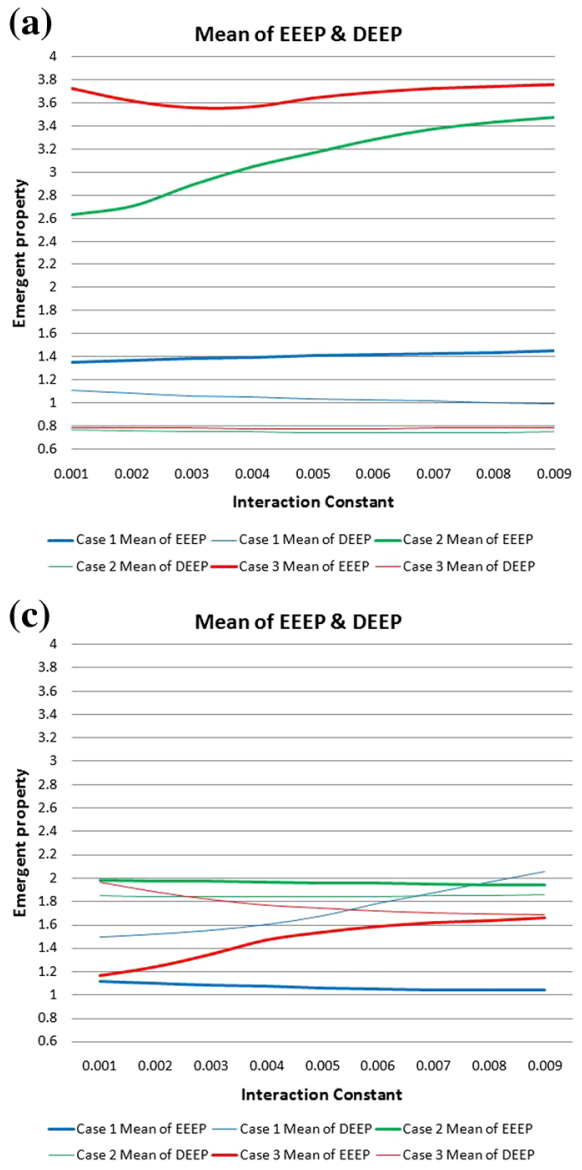

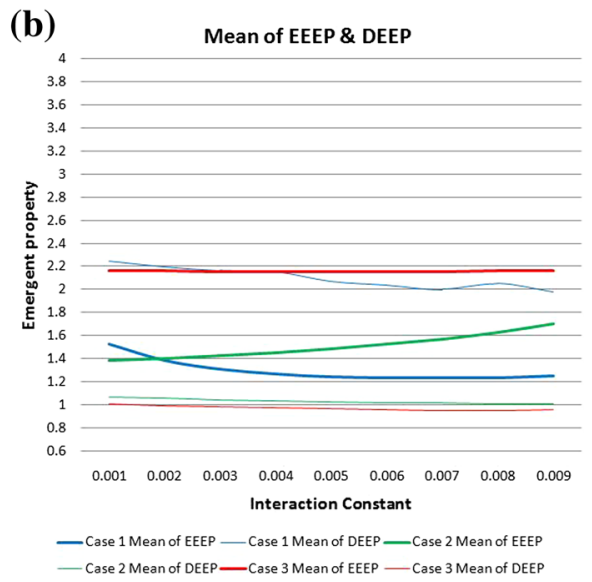

Fig. 9 a Mean of EEEP and DEEP of Case 1, Case 2, and Case 3 from Nagpur for value of $k=0.001-0.009$. Computer rendering: Author. b Mean of EEEP and DEEP of Case 1, Case 2, and Case 3 from Hyderabad for value of $k=0.001-0.009$. Computer rendering: Author. c Mean of EEEP and $D E E P$ of Case 1, Case 2, and Case 3 from Vijayawada for value of $k=0.001-0.009$. Computer rendering: Author

in time for $k=0.003$ and 0.004 . The rate of the decrease and increase in EEEP goes higher in time with higher values of $k$ and also shows a uniform decrease in later stages. Whereas the variation in DEEP in time, and different values of $k$ is negligible. Mean of EEEP is higher than the mean of $D E E P$, which corresponds to the real world. Mean of EEEP is approximately four times the mean of DEEP (Figs. 6, 9a).

\section{Hyderabad}

- In Case 1, Sagar Plaza, Abids, EEEP falls considerably with time and increase in $k$. The reversal in fall of EEEP is observed beyond value of $k=0.004$ onwards. The reversal in EEEP occurs earlier with increase in $k$. DEEP 
decreases with time and rate of decrease goes higher with increase in $k$. It is observed that the mean of DEEP is higher than the mean of EEEP which corresponds to the real world. The mean of DEEP decreases with increase in $k$ except for $k=0.008$ where reversal is observed. The mean of EEEP decreases with increase in $k$ but shows reversal at $k=0.009$ (Figs. 7, 9b).

- In Case 2, MPM Mall, Abids, EEEP rises and DEEP falls with time and increase in the value of $k$. The rate of rise in EEEP increases with an increase in $k$, whereas not much variation in the fall of DEEP is observed. The mean of EEEP rises considerably, and the mean of $D E E P$ falls gradually with an increase in $k$. It is observed that the mean of EEEP is higher than the mean of $D E E P$ which corresponds to the real world (Figs. 7, 9b).

- In Case 3, Koti, EEEP remains uniform with time and for the value of $k=0.001-0.003$, but a gradual rise is observed with an increase in $k$ beyond 0.004 . DEEP gradually falls with time and a slight increase in the rate of fall of $D E E P$ is observed with an increase in $k$. The mean of EEEP is twice the mean of DEEP and also not much variation is observed with an increase in $k$ (Figs. 7, 9b).

Vijayawada

- In Case 1, Big Bazaar Complex, EEEP falls gradually with the time and increase in $k$. EEEP shows reversal for value of $k=0.007$ and more, also reversal is observed earlier for increase in value of $k=0.007$ and above. The rate of rise in $D E E P$ increases with time and increase in $k$. For rise in DEEP repetition of pattern is observed with time. It is observed that the mean of $D E E P$ is higher than the mean of EEEP which corresponds to the real world. The mean of DEEP is 1.5 times higher than the mean of $E E E P$ for value of $k=0.001$ and rises up to twice the mean of EEEP. The rise in the mean of DEEP increases considerably beyond value of $k=0.004$ (Figs. 8, 9c).

- In Case 2, Kalamandir Complex, EEEP is uniform with time and values of $k=0.001$ and 0.002 . EEEP falls gradually with the time and increase in the value of $k=0.003$ and onwards. Not many variations are observed in DEEP, except for a rise in later part of time and increases with an increase in $k$. The mean of EEEP is higher than the mean of $D E E P$ for all values $k$, which corresponds to the real world. The difference between mean of EEEP and mean of DEEP is very small (Figs. 8, 9c).

- In Case 3, Electronic Complex, EEEP rises with the time and increase in $k$. The rate of the rise in EEEP increases with the time and increase in $k$ up to 0.003 . Beyond the value of $k=0.004, E E E P$ stabilizes and a gradual fall is observed with time. Stabilizing and gradual fall in EEEP occurs earlier with an increase in value of $k=0.004$ onwards. The rate of fall in $D E E P$ is uniform initially and increases with time and increase in $k$ up to 0.003 . Rate of fall of DEEP decreases with time for $k=0.004,0.005$ and stabilizes for $k=0.006$. Fall of $D E E P$ shows reversal for $k=0.007$ onwards and occurs earlier with increase in $k$. The mean of $D E E P$ is higher than the mean of EEEP, which does not correspond to the real 
world, however the difference between both emergent properties decreases with increase in $\mathrm{k}$ and becomes almost equal at $k=0.009$ (Figs. 8, 9c).

\section{Conclusions}

EPPR 3.1 is an agent-based model of the public realm, and is helpful in experimenting with emergent properties EEEP and DEEP of the public realm which is difficult in the real world. It provides an effective insight into the emergence of encroachments in an urban environment.

For Case 1 (the un-encroached public realm) the model produces DEEP much higher than EEEP corresponding to the real world except for the case in Nagpur, where $E E E P$ is higher than $D E E P$, but the difference is negligible. For Case 2 (the encroached public realm) the model produces EEEP much higher than DEEP corresponding to the real world. For Case 3 (the encroached public realm and speciality market) the model produces EEEP much higher than DEEP corresponding to the real world, except for the case in Vijayawada, where for the higher interaction constants it partially does not correspond to the real world.

The model largely produces emergent properties across the cases which correspond to the real world. The model generates appropriate emergent properties for all the assumed values of interaction constant, representative of commonly observed cumulative change in the urban environment ranging from 5 to $50 \%$ in a year. This reveals that the assumed interconnected and interdependent elementary properties of individual elements and their relationship for emergent properties EEEP and DEEP are valid.

Whichever is the higher value of EEEP and DEEP determines the dominating emergent property of the public realm. It is also important to note that the higher the difference by which one emergent property is higher than the other is instrumental in deciding the degree of dominance of an emergent property, leading to the emergence or non-emergence of encroachments in the public realm.

The variations in the emergent properties EEEP and DEEP are higher the higher the interaction constants i.e. pace of change in an urban environment. The variations observed in $E E E P$ with respect to time and different interaction constants are higher than DEEP. This justifies EEEP as highly sensitive as compared to DEEP. This higher variation in EEEP and its high sensitivity can have unpredictable consequences in the public realm. This is the primary reason why it is difficult in the real world to design, implement and manage the public realm in an urban environment, specifically dealing with the issue of encroachments. EPPR 3.1 offers effective predictability for the emergence and non-emergence of encroachments in the public realm and can provide insight into the above-mentioned issue.

The elementary properties of the elements of the public realm are fairly under the control of urban designers. As a designer, if one is able to intervene into these elementary properties of the individual elements of the public realm, then one can harness the desired EEEP and DEEP in the public realm, leading to fair control on the emergence and non-emergence of encroachments in an urban environment. To harness emergent properties-EEEP and DEEP, further experiments are needed to 
quantify the resultant variation in emergent properties due to trivial changes in the elementary properties of the public realm. EPPR 3.1 is an important agent-based model for conducting such experiments. EPPR 3.1 provides a computational framework that can assist designers in the design of the public realm that maintains the desired level of EEEP and DEEP.

Although efforts were made to model the public realm as close as possible to the real world, the fact remains that EPPR 3.1 is a deterministic model. The model can be further developed as a non-deterministic model, which can take it closer to the real world of the public realm. This can be done by introducing procedures for randomly selecting the interaction constant for different interactions amongst individual properties over time. The introduction of agents representing humans, which further facilitates the interactions of elementary properties amongst each other, can further strengthen the model. Overall improvements in the model addressing adaptation, stochasticity, and coevolution can aid in modelling the public realm for emergent properties in a better manner. This is the agenda for further research work and would be addressed in future publication.

\section{References}

Barnett, J. 1974. Urban design as public policy: practical methods for improving cities. New York: Architectural Record Books.

Berryman, M. 2008. Review of software platforms for agent based models. Edinburgh South Australia: Land Operations Division, Defence Science and Technology Organisation.

Bhowmik, S.K. 2005. Street vendors in Asia: a review. Economic and Political Weekly, 28 May-4 June, 2256-2264. http://www.inclusivecities.org/pdfs/4_Bhowmik_Asian_Hawkers_EPW.pdf.

Duarte, J.P., Rocha, J., Ducla-Soares, G., and Caldas, L.G. 2006. An urban grammar for the medina of Marrakech. In Design computing and cognition '06, ed. J. Gero. Netherlands: Springer.

Felsen, M., Watson, B., and Wilensky, U. 2006. Urban complexity + emergence: procedural modeling of city activity and form. In Conference proceedings: SURFACING URBANISMS, recent approaches to metropolitan design 2006. Association of Collegiate Schools of Architecture (ACSA) Woodbury University, October 12-15, 2006, Pasadena, California.

Fromm, J. 2004. The emergence of complexity. Kassel: Kassel University Press.

Fuchs, C. 2003. Structuration theory and self-organization. Systemic Practice and Action Research 16(2): $133-167$.

Gaus, G. 2011. Explanation, justification, and emergent properties: an essay on Nozickian metatheory. In Cambridge companions to Nozick's Anarchy, State, and Utopia, ed. R.M. Bader, and J. Meadowcroft. Cambridge: Cambridge University Press.

Jervis, R. 1998. System effects: complexity in political and social life. Princeton: Princeton University Press.

Johnson, C.W. 2006. What are emergent properties and how do they affect the engineering of complex systems? Reliability Engineering and System Safety 91(12):1475-1481.

Mitleton-Kelly, E. 2003. Ten principles of complexity and enabling infrastructures. In Complex systems and evolutionary perspectives of organisations: the application of complexity theory to organisations, ed. E. Mitleton-Kelly. Oxford: Elsevier.

Mukim, M. 2011. Industry and the urge to cluster: a study of the informal sector in India. London: Department of International Development, London School of Economics.

Patil, A.P., and A.R. Dongre. 2013. An approach for understanding encroachments in the urban environment based on complexity science, URBAN DESIGN International. Advance online publication, 17 July 2013; doi:10.1057/udi.2013.12. 
Portugali, J. 2012. Complexity theories of cities: achievements, criticism and potentials. In Complexity theories of cities have come of age: an overview with implications to urban planning and design, ed. J. Portugali, H. Meyer, E. Stolk, and E. Tan. Berlin: Springer.

Railsback, S.F., and V. Grimm. 2011. Agent-based and individual-based modeling: a practical introduction. Princeton: Princeton University Press.

Ramalingam, B., Jones, H., Reba, T., and J. Young. 2008. Exploring the science of complexity: ideas and implications for development and humanitarian efforts. London: Overseas Development Institute. http://www.odi.org.uk/resources/docs/833.pdf.

Robertson, D.A. 2005. Agent-based modeling toolkits NetLogo, RePast, and Swarm. Academy of Management Learning and Education 4, 4:524-527. http://amle.aom.org/content/4/4/524.short.

Schank, J. 2010. Agent-based modeling. http://www.agent-based-models.com/blog/2010/03/30/agentbased-modeling/.

Symons, J. 2008. Computational models of emergent properties. Minds and Machines 18(4): 475-491.

Szabo, C., and Y.M. Teo. 2013. Semantic validation of emergent properties in component-based simulation models. In Ontology, epistemology, and teleology for modeling and simulation: philosophical foundations for intelligent M\&S applications, 44, ed. A. Tolk. Berlin: Springer.

Tibbalds, F. 1992. Making people-friendly towns. London: Taylor and Francis.

Timalsina, K.P. 2011. An urban informal economy: livelihood opportunity to poor or challenges for urban governance. Global Journal of Human Social Science 11(2): 25-31.

Whyte, W.H. 1980. The social life of small urban spaces. Project for Public Spaces Incorporated.

Wilensky, U., Netlogo. (1999). http://ccl.northwestern.edu/netlogo/.

Akshay Prabhakar Patil is an Architect-Urban Designer, who completed a Bachelor of Architecture (1996) in the Department of Architecture and Planning, VRCE (VNIT), Nagpur, India and Post-graduate Diploma in Urban Design (1999) from School of Architecture, CEPT, Ahmedabad, India. He is pursuing a $\mathrm{PhD}$ with research interest in Urban Design and Complexity Science.

Dr. Alpana R. Dongre is a Professor in Architecture at Visvesvaraya National Institute of Technology, Nagpur. She has a specific interest in working across the allied disciplines of Architecture and Urban Design. Her research includes form studies through structure-architecture interaction, climate responsive design, heritage studies and architectural acoustics are of particular concern. 